\title{
INEL BNCT PROGRAM
}

VOLUME 5, NO. 9

MAR 261902

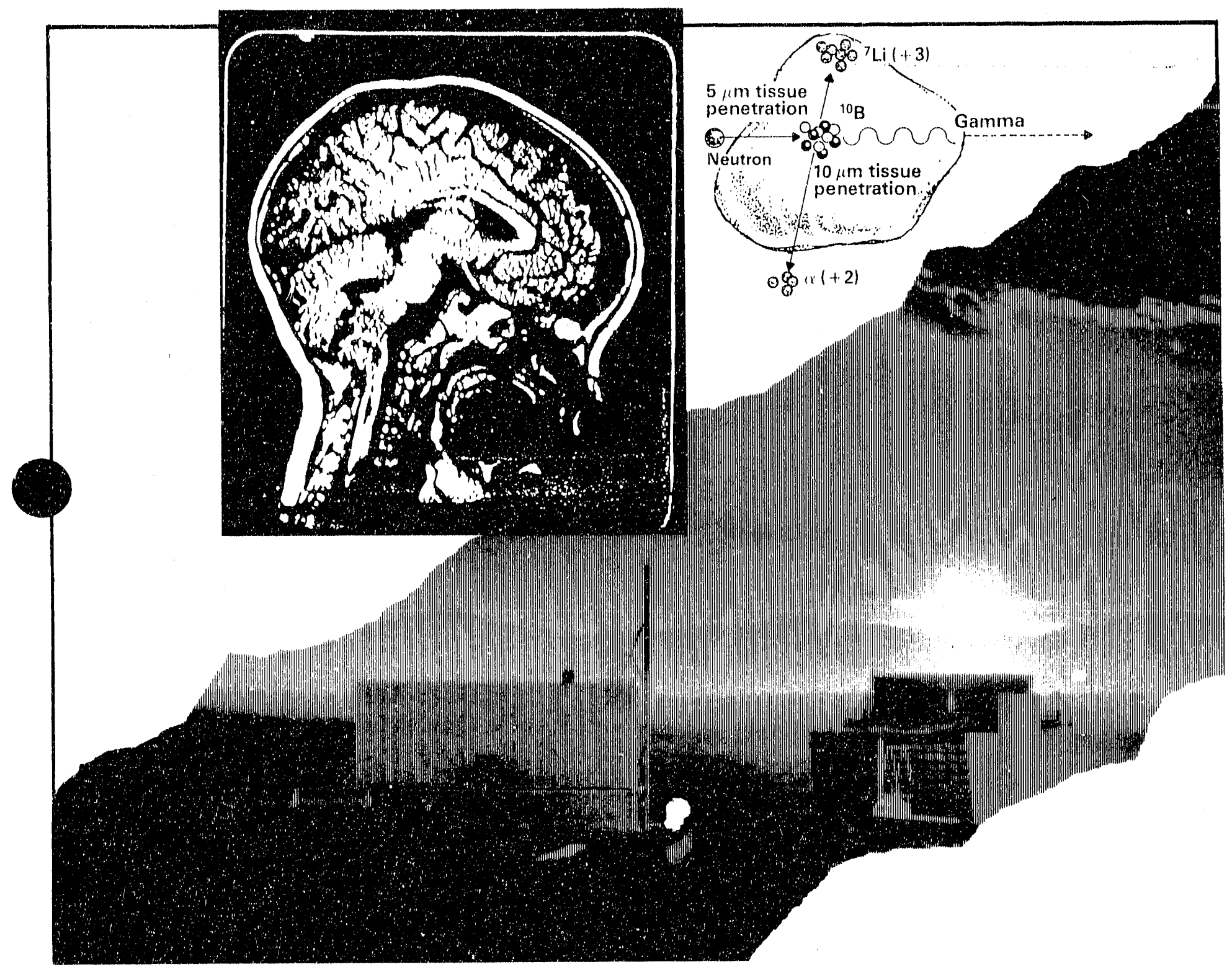

BULLETIN

Prepared for the U.S. Department of Energy

Under DOE Contract No. DE-AC(07-761D0157()

MUSUR 


\section{DISCLAIMER}

This report was prepared as an account of work sponsored by an agency of the United States Government. Neither the United States Government nor any agency thereof, nor any of their employees, makes any warranty, express or implied, or assumes any legal liability or responsibility for the accuracy, completeness, or usefuiness of any information, apparatus, product, or process disclosed, or represents that its use would not infringe privately owned rights. Reference herein to any specific commercial product, process, or service by trade name, trademark, manufacturer, or otherwise does not necessarily constitute or in ply its endorsement, recom. mendation, or favoring by the United States Government or any agency thereof. The views and opinions of authors expressed herein do not necessarily state or reflect those of the United States Government or any agency thereof. 
DE92 010836

\section{Bulletin}

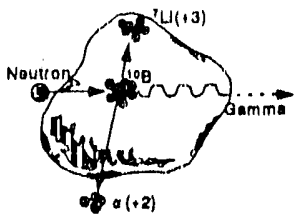

Published by the INEL BNCT Program - Arlene L. Ackermann, Editor

September 1991

\section{Introduction}

This Bulletin presents a summary of accomplish. ments and highlights of the Idaho National Engineering Laboratory's (INEL) Boron Neutron Capture Therapy (BNCT) Program for September 1991. This bulletin includes information on the brain tumor and melanoma research programs, Power Burst Facility (PBF) technical support and modificetions, PBF operations, and updates to the animal data charts.

\section{TABLE OF CONTENTS}

Introduction.

Principai Investigator's Highlights.

A. Brain Tumor Research.

Project 1: Supporting Technology

Development................

Project 2: Treatment Protocol

Development.....

Project 3: Human Pharmacokinetics .................

Project 4: Drug Interaction and Toxicity.............

B. Melanoma Research....

Project 1: Boron Localization Soreaning.............

Project 2: Biodistribution, Pharmacology, and

Toxicity of Boron Delivery Agents...... 14

Project 3: Large Animal Model Studies...............

Project 4: Melanoma Detection and Boron Quantification by Scintigraphy.................

Project 5: Boronated Low Density Lipoproteins and Amino Acid Development and Evaluation................................

Project 6: Boronated Liposome Development and Evaluation.

C. Administration

D. PBF Technical Support and Operations...............

Appendix A: Animal Data Charts....................... Appendix B: Acronyms.

\section{Principal Investigator's Highlights}

\section{A. BRAIN TUMOR RESEARCH}

1. Project 1: Supporting Technology Development

Task 1: Gross Boron Analysis

Both ICP-AES instruments are fully operational. No new samples were received this month and the majority of samples available were analyzed.

Task 2: Borocaptate Sodium (BSH) Purity Determination

Two samples were analyzed for oxidation product impurities by HPLC this month. These samples consisted of one of the Ben Venue-packaged vials of ${ }^{10} \mathrm{BSH}$ and the other was from a fresh batch of ${ }^{10} \mathrm{BSH}$ produced by Callery Chemical. The results of the chromatographic analyses are shown in Table 1. The newest material, BNCT-328, showed major contaminants of BSS and BSSO. A significant amount of $\mathrm{Na}_{2} \mathrm{~B}_{12} \mathrm{H}_{12}$ was noted.

Task 3: Biochemistry of BSH and Its Oxidation Products (Active Form Identification)

University of Utah researchers have begun studies on $\mathrm{BSH}$-albumin interactions using high field nuclear magnetic resonance.

Task 4: Subcellular Analytical Development Washington State University research- 
ers supplied new BSH-treated and untreated tissue samples to Atom Sciences, Inc. for SIRIS analysis. Preliminary data analysis indicates that boron contamination in the mrounting and sample preparation methodology is still a problem. Final results from this experiment will be reported in October 1991.

Task 5: Noninvasive Boron Quantification

Two different canine pharmacokinetic studies were conducted at the University of Utah MRI center using the new projection reconstruction imaging techniques. In the first study, the first scan was during $\mathrm{BSH}$ infusion and the rernaining scans were during the elimination phase. Results are pendiig. In the second study, four imaging scans were performed during the elimination phase. Results from this study will be presented in October 1991.

Task 6: Measurement Dosimetry

Analysis of neutron activation data from the epithermal neutron beam at the High Flux Reactor at Petten, The Netherlands, resulted in a neutron spectrum shown in Figure 3. This data is being reviewed by the ECBNCT staff. Results were presented at the September 18-20, 1991 international Workshop in Petten.

Dosimetry support was carried out for nine dogs scheduled for dose-ranging studies at BMRR. Development of a realtime system to measure the boron capture rate in irradiation subjects is continuing. Dosimetry experiments in support of this development were performed at BMRR on August 29, 1991. Fesults are pending.

Task 7: Analytical Dosimetry

A summary of the past fiscal year status of the medical imagery recon- struction software development is included. Details of methodology developed over the course of this year are being submitted to publication in the Journal of Nuclear Science and Engineering. Many additional and desirable optional features for bnct edit have been identified and are being pursued. A replacement machine for the Apollo DN10000 is anticipated early in FY-92. Finally, microdosimetric calculations were perfomred to assit in assessing differences in $\mathrm{BSH}$ and BPA performance. An interesting finding suggests that, for the same tumor dose, the dose to the endothelial nucleus of the at-risk normal tissue would increase by $69 \%$ with BPA as compared to $\mathrm{BSH}$.

\section{Project 2: Treatment Protocol Development} Task 1: Large Animal Studies

Four new patients with spontaneouslyoccurring brain tumors were entered into the Program during late August and early to mid-September 1991. These animals are in various stages of analysis. Summaries of other living or recently expired brain tumor dogs are included in this bulletin.

Nine additional dogs were scheduled for dose-ranging studies at BMRR. Dogs already recently irradiation within the normal tissue-tolerance study continue to be followed. No additional dogs have been infused in the pharma. cokinetic study.

Task 2: Pituitary Tumor Treatment Evaluation Studies

Experiments are continuing at Oregon Health Sciences University (OHSU) to evaluate the stimulation of pituitary tumor cells in-vitro for use in ultimate evaluation of the effect of neutron exposure on these cells. The Research Endocrine Laboratory at the OHSU reactor facility is being completed. 
The staff of the Oregon State University (ORSU) reactor facility continue to define parameters required for planned pituitary cell irradiations.

\section{Project 3: Human Pharmacokinetics}

The University of Utah Boron Project Interest Group held its inaugural meeting on August 27, 1991. Discussion revolved around specific plans for implementation of human pharmacokinetic studies at the University of Utah.

\section{Project 4: Drug Interaction and Toxicity}

No reportable progress this month.

\section{B. MELANOMA RESEARCH}

\section{Project 1: Boron Localization Screening}

Liposome BNCT compound was evaluated in 48 tumor-bearing BDF mice. Preliminary results are shown in Table III. Further analyses of this data are pending. Preparations are underway to complete two liposomal delivery assays per month.

2. Project 2: Biodistribution, Pharmacology, and Toxicity of Boron Delivery Agents

Task 1: BPA/Molecusol/DEA Availability Study

There is still a backlog of physiologic data acquired from the previous canine experiments at Idaho State University (ISU). Analysis of this data will be possible soon pending debugging of the data transfer system and DATAPAC-ll software.

\section{Task 2: Toxicological Evaluation of BPA}

Key instrumentation in support of this task has yet to arrive at ISU. Descriptions of the uses for some of this instrumentation is included in this bulletin.

3. Project 3: Large Animal Model Studies

Potential patients for these studies continue to be identified.

4. Project 4: Melanoma Detection and Boron Quantification by Scintigraphy

A pilot study investigating the in-vivo biodistribution of an ${ }^{126} /$-radiolabelled borovaline analog in tumor-bearing mice will begin the first week of October 1991. A description of this study is included.

5. Project 5: Boronated Low Density Lipoproteins and Amino Acid Development and Evaluation

University of California/San Francisco researchers have made significant progress in finding an alternative method of isolating humn low-density lipoproteins from plasma. Results of some of these studies are included in Figures 4-6.

6. Project 6: Boronated Liposome Development and Evaluation

A description of small animal studies of the most recent boronated liposome development compound are included. Additional new boron species candidates for liposomal delivery is continuing. Some of these candidate species for liposomal delivery are included. 


\section{ADMINISTRATION}

The INEL BNCT Research Program and PBF will begin the new fiscal year without knowledge of the FY-92 budget and both areas will continue at the same level of effort in the new fiscal year as at present.

Five papers were submitted to DOE for approval and clearance prior to submission for publication and the titles and authors of these publications are included.

\section{PBF TECHNICAL SUPPORT AND OPERATIONS}

PBF Operations: A DOE-ID Reactor Safety Appraisal was conducted the week of September 20, 1991 and recommendations from the 1990 appraisal were closed.

PBF Technical Support: The five-year inspection of the PBF cananl permanent and temporary fuel storage racks was completed. No degradation of the carial rack structure or poison integrity was found.
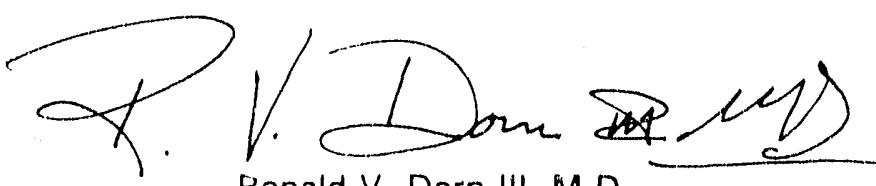

Ronald V. Dorn III, M.D.

Principal Investigator

INEL BNCT Program 


\section{A. BRAIN TUMOR RESEARCH}

Project 1: Supporting Technology Development

\section{Task 1: Gross Boron Analysis}

Samples received

Samples prepared for analysis $\quad \sim 380$

Samples analyzed $\quad \sim 480$

Backlog:

Awaiting preparation $\quad \sim 20$

Prepared, awaiting analysis $\quad \sim 40$

Both inductively coupled plasma-atomic emission spectroscopy (ICP-AES) instruments are still fully operational. No new samples were received this month. The only samples remaining are from Washington State University (WSU) from mice injected with boron-containing liposomes provided by University of California/Los Angeles (UCLA) researchers. Samples analyzed were from Project 1, Task 3, cells cultured at WSU, and dogs from Project 2 studies at WSU. Difficulties were encountered with the analyses of carborane samples from the University of California/San Francisco (UCSF). Attention will be returned to these samples when all of the mice samples have been run.

Task 2: Borocaptate Sodium (BSH) Purity Determination

Two samples were analyzed for oxidation product impurities by high performance liquid chromato- graphy (HPLC) this month. The first, BNCT-267, was one of the Ben Venue-packaged vials of ${ }^{10} \mathrm{BSH}$ that had been inadvertently misplaced in uncontrolled storage while enroute to Brookhaven National Laboratory (BNL). The second, BNCT-328, was from a fresh batch of ${ }^{10} \mathrm{BSH}$ produced by Callery Chemical. Additional samples analyzed were BNCT-217 for comparison to BNCT-267, BNCT320, and BNCT-202. BNCT-320 and BNCT-202 are both natural boron abundance BSH. BNCT-202 was run as a control and BNCT-320 was run to confirm the previous analysis. The results shown in Table I for BNCT-320 include the original analysis (see August 1991 Bulletin).

Results of all chromatographic analyses are shown in Table 1. Sample chromatograms comparing BNCT-328 with BNCT-267 and BNCT-202 are shown in Figure 1. Results for BNCT-267 appeared to be somewhat inconsistent. Weighing and dilution errors were the suspected causes. To determine the extent of these errors, the samples prepared for HPLC were also diluted for ICP-AES analysis of sulfur, boron, and nitrogen. As suspected, weighing errors had occurred and the results for this sample were corrected, assuming that the sample only contained sulfur, boron, nitrogen, and hydrogen. The hydrogen content was determined from the boron content as it was assumed there was a 1:1 relationship of boron to hydrogen. No change was apparent in BNCT-267 as a result of uncontrolled storage.

The chromatograms indicate the newest material, BNCT-328, has major contaminants of BSS and BSSO and some late eluting peaks similar to that found in BNCT-202. Examination of the elemental ratios in Table II indicate an additional problem with BNCT-328. The boron:sulfur and nitrogen:sulfur ratios are significantly different from the rest,

Table I. Results of HPLC Analysis of Several BSH Samples.

$\begin{array}{ccc}\text { Vial Number } & \left.\text { BSS }^{4 \cdot(w t} \%\right) & \frac{\text { BSSO }^{4} \cdot(w t \%)}{202} \\ 0.98 \pm 0.09 & 0.11 \pm 0.02 \\ 217 & 0.1 & 0.37 \\ 267 & 0.20 \pm 0.07 & 0.35 \pm 0.02 \\ 320 & 0.25 \pm 0.02 & 0.59 \pm 0.56 \\ 32.8 & 1.4 \pm 0.2 & 0.41 \pm 0.04\end{array}$




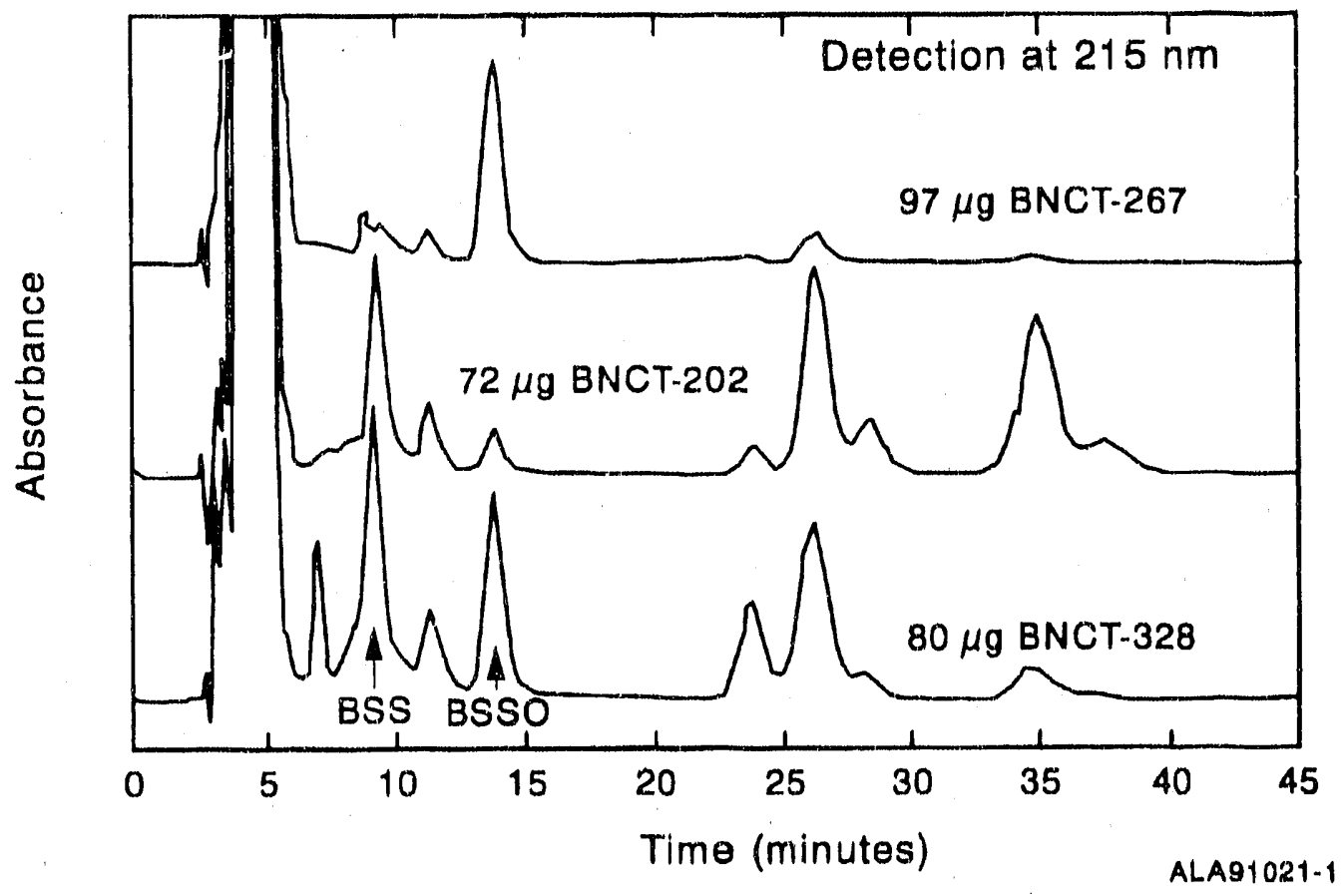

Figure 1. Comparison of chromatograms of new BSH with older BSH.

Table II. Mole Ratios for Various BSH Samples Determined by ICP-AES.

\begin{tabular}{cccc}
\hline Vial Number & Eoron/Sulfur & $\begin{array}{c}\text { Mole Ratio } \\
\text { Boron/Nitrogen }\end{array}$ & Nitrogen/Sulfur \\
\hline Expected & 12.0 & 6.0 & 2.0 \\
202 & 12.7 & 6.4 & 2.0 \\
$210^{\circ}$ & 12.4 & & \\
217 & 12.9 & 6.2 & 2.1 \\
267 & 13.2 & 6.5 & 2.0 \\
320 & 13.1 & 6.6 & 3.5 \\
328 & 21.3 & 6.1 & \\
\hline
\end{tabular}


indicating the presence of some $\mathrm{Na}_{2} \mathrm{~B}_{12} \mathrm{H}_{12}$. This latter compound elutes very near or within the BSH peak with the chromatographic conditions used and was, therefore, not detected. Callery Chemical reexamined the product and determined there was as much as $40 \% \mathrm{Na}_{2} \mathrm{~B}_{12} \mathrm{H}_{12}$ present. The ${ }^{10} \mathrm{~B}$ nuclear magnetic resonance (NMR) spectra shown in Figure 2 clearly indicates that significant $\mathrm{B}_{12} \mathrm{H}_{12}{ }^{2}$ is present. Using the peak areas and heights from these spectra, it was determined that $32-38 \%$ of the boron present in the sample was in the form of the $\mathrm{B}_{12} \mathrm{H}_{12}{ }^{12 \cdot}$ anion. Since the compound had already been shipped to WSU, they were immediately informed as to the chemical composition of this product. NMR spectroscopy has been performed on samples of nearly every batch of BSH received to date, but usually in the form of a spectroscopy experiment, as opposed to a quality determination. No other samples used for the spectroscopy experiments have exhibited noticeable $\mathrm{B}_{12} \mathrm{H}_{12}{ }^{2}$ contamina tion.

Because of the problems associated with BNCT. 328 , all new material will be rigorously screened by a multitude of techniques, including HPLC, NMR, IR, ICP-AES, and carbon-hydrogen-nitrogen (CHN) analysis prior to making any quality determinations as to the purity of the incoming compound. The HPLC analysis will be run under two sets of conditions:
(1) optimum for determination of the oxidation products and (2) optimum for species with retention characteristics very similar to BSH. No assumptions as to types of ralyses already per. formed or the quality of the incoming material can be made at this time.

\section{Task 3: Biochemistry of BSH and Its Oxidation Products}

All INEL ICP-AES analysis results have been completed and the data are being interpreted. HPLC procedures to separate the major molecular weight fractions of serum proteins are ready for use in determining which serum proteins are associated witil the boron compounds.

University of Utah (UofU) researchers have begun studies on $\mathrm{BSH}$-albumin interactions using high field nuclear magnetic resonance (NMR). At the "B frequency of $160.4 \mathrm{Mhz}$, the well-established features of BSH are seen. However, because of background signal from borosilicate sample tubes and probe insert, researchers are unable to lower sample concentrations to levels desired for analyses. Quartz glass substitutes have been ordered and work continues with proton observations at $500 \mathrm{Mhz}$.

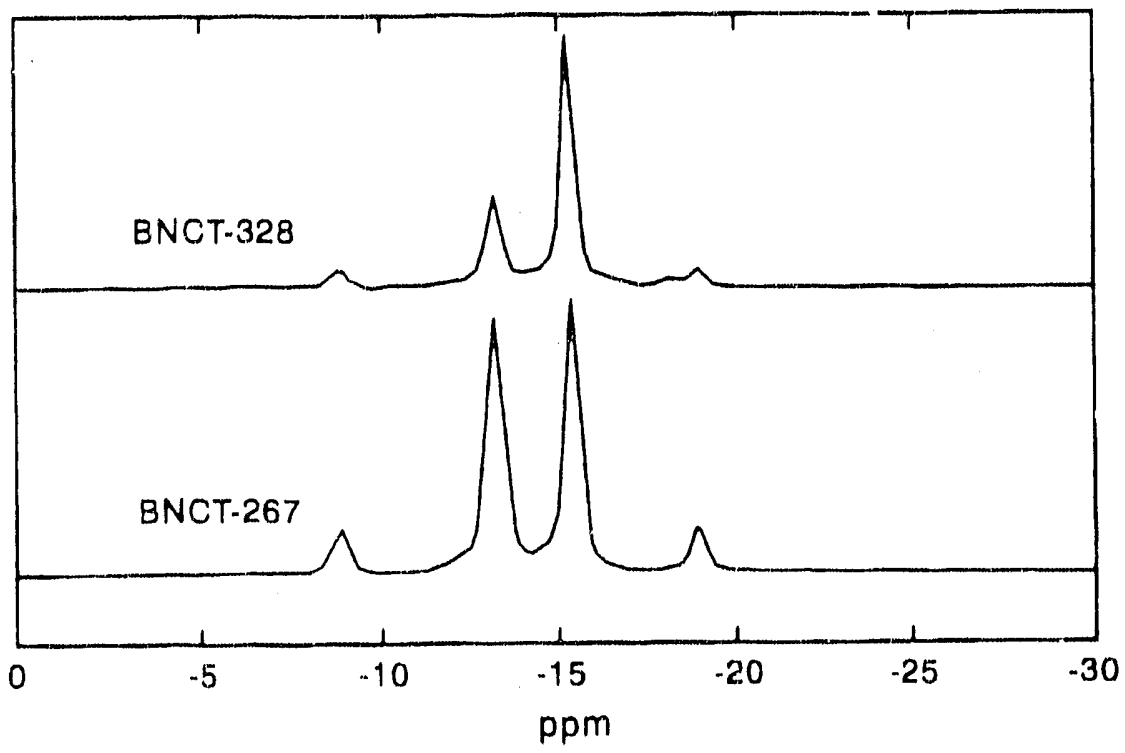

ALA $102 \% 2$

Figure 2. ${ }^{10} \mathrm{~B}$ NMR of different BSH lots from Callery. BNCT-328 is the new material, BNCT-267 is material packaged by Ben Venue. 
Task 4: Subcellular Analytical Development

Task 4A: Se zondary lon Mass Spectrometry (SIMS)

No samples were submitted for analysis this month.

Task 4B: Sputter-Initiated Resonance Ionization Spectroscopy (SIRIS)

New BSH-treated and untreated tissue samples mounted on Atom Sciences, Inc. (ASI)-supplied silicon wafers were received at Atom Sciences from WSU. The SIRIS ion beam was optimized for approximately 15 micrometer resolution. A number of brain section and retina sections were analyzed for boron distribution. Analyses consisted primarily of transverse scans. Ion-beam burn spots were made at the encls of the scans to visually verify the scanned positions. Photos at $X 50$ magnification were taken after analysis to register the SIRIS data with tissue morphology. Preliminary data analysis indicates that boron contamination in the mounting and sample preparation methodology is still a problem. Data analysis will be completed and reported in October 1991.

\section{Task 4C: Alpha Track-Etch}

The original task is currently being brought to a close at Idaho State University (ISU). A few experiments are being rerun and photographs retaken for verification. A final report is in preparation.

\section{Task 5: Noninvasive Boron Quantification}

University of Utah: Two differing canine pharmacokinetic studies were conducted at the UofU mag. netic resonance imaging (MRI) senter using the new projection reconstruction imaging techniques. The first dog was a $19 \mathrm{~kg}$ female, breed unknown. Five scans were taken, each lasting eight minutes. The first scan was during BSH infusion and the remaining scans were during the elimination phase.
The total study lasted 161 minutes. Necropsy was performed within a hour after euthanasia. Wholehead spectroscopy was also performed and blood samples collected. Tissue and blood samples will be analyzed by ICP-AES.

The second study involved a $20.5-\mathrm{kg}$ male, breed unknown. Four imaging scans were performed during the elimination phase. Whole-head spectroscopy and blood samples were acquired during the scudy, which lasted 169 minutes. The studies have been shortened because of the inclusion of proton imaging preceding the studies and a necessity to terminate the studies before the start of clinical imaging. The results of both studies, including boron correlation to proton images, will be presented next month.

Northwest Imaging, Inc.: No reportable progress.

Stanford University: The imaging experiments at the UofU are being supported by Dr. Gary Glover, who is providing enhanced imaging and reconstruction software.

\section{Task 6: Measurement Dosimetry}

Neutron and Gamma Field Measurements: Analyses of neutron activation data from the epithermalneutron beam at the High Flux Reactor (HFR) at Petten, The Netherlands, indicates the neutron spectrum shown in Figure 3 . The spectium data and the neutron and gamma field data for cylindrical and beagle-head phantoms have been transmitted to European Collaboration on Boron Neutron Capture Therapy (ECBNCT) staff for review and comment. In addition, INEL researchers have authorized ECBNCT participants to present the results at the September 18-20, 1991 International Workshop (see $r$ dministration/Meetings) at Petten. The measured epithermal-neutron flux was approximately $5.0 E 8 \mathrm{n} / \mathrm{cm}^{2} / \mathrm{sec}$, whereas, the value predicted by the design calculations was a factor of 2.6 greater $\left(1.3 \mathrm{Eg} \mathrm{m} / \mathrm{cm}^{2} / \mathrm{sec}\right)$.

The design calculations have been reviewed and an error found in the cross-section data used for argon. The revised calculations are reported to be in better agreement with the measured data. The measured and calculated fast-neutron flux and 


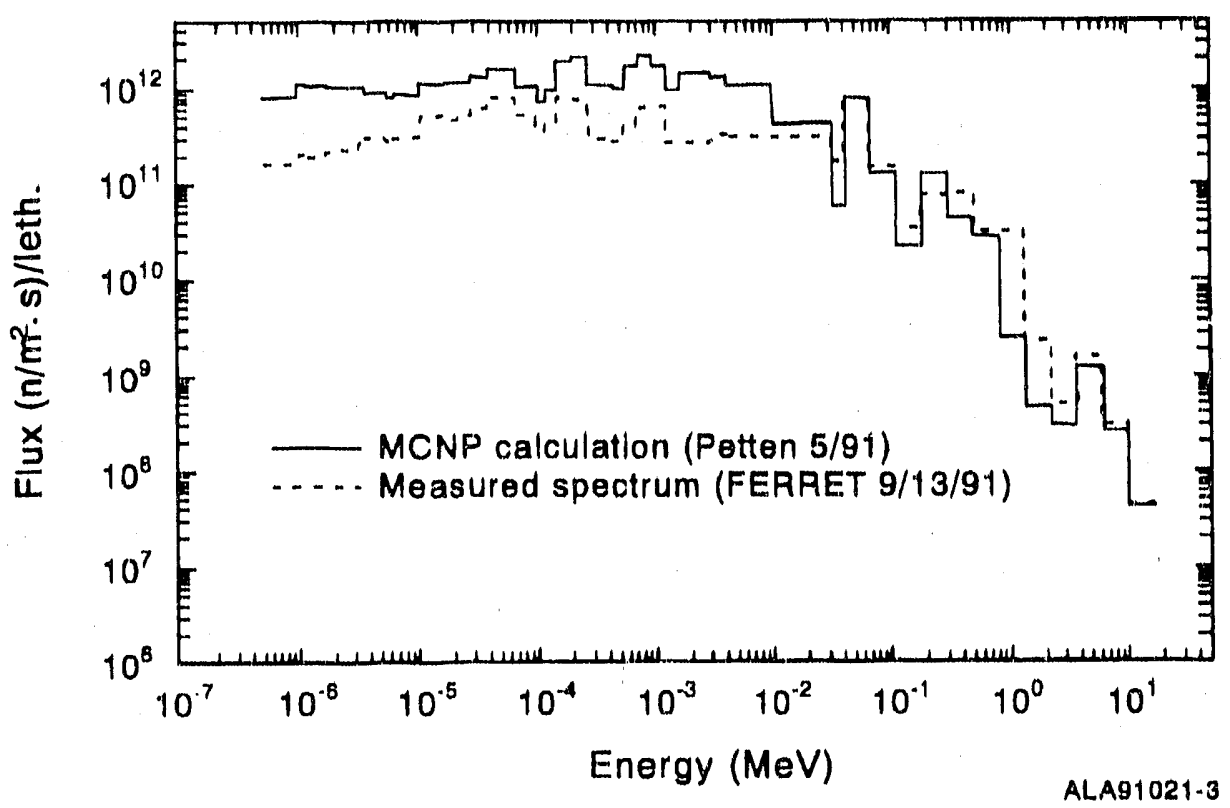

Figure 3. Neutron spectrum for Petten BNCT beamport.

resulting dose are in reasonable agreement. The free-field, fast-neutron KERMA per epithermal neutron is approximately $9.0 \mathrm{E}-11 \mathrm{cGy} / \mathrm{n} / \mathrm{cm} / \mathrm{sec}$, which is about a factor of 2 greater than the BMRR epithermal-neutron beam. However, HFR beam collimation will reduce differences under treatment conditions that necessarily include beam delimiting at BMRR.

Dosimetry for Canine Studies: Nine dogs were scheduled for dose-ranging studies at BMRR. The studies included irradiations at boron concentrations "rom 25-100 ppm and doses from 2700-3100 cGy. Confirmatory dosimetry measurements were conducted for each irradiation. The boron concentration for the last irradiation was scheduled to be $25 \mathrm{ppm}$, but the blood concentration ineasurements indicated $90 \mathrm{ppm} 120$ minutes after the start of infusion. This concentration level would have required an unacceptable wait time to reach the $25 \mathrm{ppm}$ level and the irradiation was revised to a boron concentration of $50 \mathrm{ppm}$.

Realtime Dosimetry Development: The development of a realtime system to measure the boron capture rate in irradiation subjects is continuing. Dosimetry experiments were performed at BMRR on August 29, 1991 and the results of these tests were analyzed this month. The test series evaluated a detector system's ability to measure the 478 kev gamma ray intensity in the presence of the background radiation, particularly the $511 \mathrm{keV}$ gamma ray produced by positron annihilation. The detector, produced by EV Products, Inc., is a compact photodiode coupled to a cesium lodide scintillation crystal. The compact size of this detector and preamplifier is attractive because it reduces the amount of shielding required to suppress the background at the detector to acceptable levels. Preliminary results indicate that the $478 \mathrm{keV}$ gamma intensity can be measured in the presence of a much more intense $(\times 10) 511 \mathrm{keV}$ gamma field. The encouraging results warrant furthe: experimental testing. 


\section{Task 7: Analytical Dosimetry}

Task 7A: Dosimetry Software/Alpha 1 Software Development:

The following is a fiscal year-end summary of the status of the medical image reconstruction software development task being performed by INEL researchers in collaboration with Montana State University (MSU).

Early in FY-91, UofU delivered the final version of the bnct_edit program. Shortly afterwards, the geometry file from bnct edit was connected to the INEL BNCT Monte Carlo program via UofU's Personal Ray Tracer (PRT). When the Monte Carlo code is tracking through the B-spline surfaces created by bnct_edit, it invokes PRT to compute the surface intersection given a starting point in threedimensional space and a set of direction cosines. This new method of tracking through free-form surfaces has been validated against experiment and independent geometric models. The details of this method have been summarized and are being submitted to publication in the Journal of Nuclear Science and Engineering.

During the initial use of bnct edi $i_{2}$, many additional desirable operational features were determined, even though the Uofu collaborators fulfilled all of the contract specifications. The UofU researchers had implemented all of the graphics features of bnct edit in Apollo-proprietary graphics primitive resource (GPR) as $X 11$ was not available at the time development began. Bocause many of the absent features could be better implemented using $\times 11$, $X 11$ would be more portable, and Hewlett-Packard (HP)-Apollo appeared to be phasing out GPR, it was decided to rewrite bnct_edit in $\times 11$. With the support of MSU staff and research assistants, this effort was undertaken at MSU in February 1991. Originally, the plan was to "wrap" all of the necessary $\times 11$ graphics calls with an equivalent GPR function, then, at a later time, rewrite the entire code. Two to three weeks into the initial conversion, it was evident that the expedient approach would not work, primarily because of event handling differences between GPR and $X$. At this point, rewriting of the entire code began. With the assistance of a graduate research assistant and, later, a faculty member, the entire UofU menuing paradigm was rewritten. At this time, image editing features, along with three-dimensional reconstruction, are being implemented in $X 11$ with the goal of providing this capability by the end of FY-91 or the beginring of $F Y-92$.

The Apollo DN10000 is agliain down with major problems. Since June $19 \mathrm{gl}$, availability of this workstation has been less than $50 \%$ and unavailability is impacting progress. HP is aware of the problem and has offered a replacement machine (HP.750) with a deep price discount, equivalent to a credit for what the Program is currently paying for the DN10000. As soon as FY-92 funds are authorized, it is planned to purchase a replacement mahcine.

\section{Task 7B: Canine Dosimetry Analysis}

No canine brain-tumor analyses were required during September 1991. Development of the rat model continues in support of the proposed IJniversity of Rochester studies.

\section{Task 7C: Database Management System}

Database development and data entry are ongoing at WSU. Networking between INEL, WSU, MSU, and JRC-Petten is operational and in regular use.

\section{Task 7D: Biophysics/Stochastic Model Develop- ment}

Microdosimetric calculations were performed to assist in assessing differences in BSH and BPA performance. Tumor cells were represented as 10 $\mu \mathrm{m}$ spheres with $5-\mu \mathrm{m}$ nuclei and $14 \%$ extracellular space. Endothelial cells were represented with a 5 $\mu \mathrm{m}$ inner diameter and a $7-\mu \mathrm{m}^{3}$ nuclear volume. Analyses, assurning experinentally indicated macrodistributions, suggest that, for the same tumor dose, the dose to the endothelial nucleus would increase by $69 \%$ with BPA, as compared to BSH.

Task 7E: Neutron Source Analysis

No reportable progress. 
Task 7F: Georgia Institute of Technology Res. earch Reactor (GTRR) Physics Feasibility Study

Development of a three-dimensional Monte Carlo computer code (MCNP) calculational model of the as-built GTRR core has begun. The model will be benchmarked against critical experiments.

\section{Project 2: Treatment Protocol Development}

\section{Task 1: $\quad$ Large Animal Studies}

Spontaneously-Occurring Brain Tumors: "Lady Windsor" Negus (\#35447-160), a 13-year old female Springer Spaniel, was admitted to WSU on August 28, 1991 with an acute onset of weakness and ataxia in all four limbs. A small enhancing lesion in the medullary region extending caudally into the hind brain was seen on computed tomography (CT) scan. She was not admitted into the Program because of deterioration of her renal function and was sent home with her owners.

"Pippin" O'Brien (\#35447-161), an eight-year old male Schnauzer, was admitted to the Program on September 16, 1991 for ataxia, spasms, and progressive behavioral changes. He has become more aggressive over the past eight weeks. An enhancing, mineralized mass just rostral to the lateral ventricles in the region of the cingulate gyrus was seen on CT scan. An MRI is scheduled for September 28, 1991.

"Sam" Wilson (\$35447-162), a five-year old spayed female Shepherd cross, was admitted to the Program on September 18, 1991 for circling to the left, staggering, running into objects, and slight personality-behavior changes. An enhancing lesion in the left frontal lobe just dorsal to the cingulate gyrus was seen on CT scan. An MRI is scheduled for September 28, 1991.

"Licorice" Jewkes (\#35447-159), a 12-year old female Dachshund/Cocker cross (admitted to the Program on August 12,1991), received CT and MRI scans and no abnormalities were observed. She was sent home to her owners.
"Niki" Woods (\#35447-158), a five-year old female, spayed Samoyed (who underwent brain surgery in August 1991), is doing well. She returned to WSU for a followup MRI that showed the left frontal ethmoidal cyst has been decompressed.

"Bessie" Blish (\#35447-155), a 12-year old female Golden Retriever, was treated at BMRR August 9, 1991, but died three days later. Histologic exam of the brain is complete and abnormalities were limited to the tumor, which was a meningioma. Necrosis of the tumor was not evident.

"Dudley" Fiset (\#35447-151), a six-year old castrated, male Golden Retriever, is doing well.

"Sugar" Ellsworth (\#35447-142), a seven-year old spayed, female Boxer, was euthanized in July 1991. Initial histological results on the brain ire complete. Thera was severe, multifocal necrosis of the white matter surrounding the lateral ventricles. The rest of the brain was unaffected. The mass in the brainstem was either a choroid plexus adenoma or a meningioma. Further evaluation is being performed to identify the tumor type. Necrosis of the tumor was not evident. The white matter necrosis is similar to the changes seen in the 30-and 50-Gy raaiation dose-tolerance dogs.

"Muffy" Lower (\#35447-140), a four-year old spayed, female Terrier cross, is doing well.

"Tou Wide" Marshall (\#35447-129), a four-year old female Newfoundland cross, is still having behavioral changes, but her owners are giving her time and hope she will come around to her old self.

"Brandy" Hoff (\#35447-94), a seven-year old female Golden Retriever, is still doing well.

Normal Tissue Tolerance (Neutron Irradiation): Nine dogs were scheduled for dose-ranging studies at BMRR. The studies included irradiations at boron concentrations from $25-100 \mathrm{ppm}$ and peak doses from 2700-3,00 cGy. Two dogs died during the tests. The first dog died September 24, i991, after the dog was anesthetized and just pricr to the start of the irradiation. The second dog died sometime during the night of September 27, 1991, over 24 hours following irradiation on September 26, 1991. The cause of death has not yet been determined for either dog. 
Four dogs that underwent epithermal-neutron irradiation in August 1991 experienced a return to normal of their blood counts. Three of the dogs are not showing any hair loss. The fourth dog has had hair loss and depigmentation of the skin, but it is believed this is secondary to skin biopsies rather than the irradiation itself.

All four dogs in the group at $50 \mathrm{ppm}{ }^{10} \mathrm{~g}$ and $27 \mathrm{~Gy}$ have been itradiated. Three dogs at $100 \mathrm{ppm}$ and $27 \mathrm{~Gy}$, three dogs at $100 \mathrm{ppm}$ and $31 \mathrm{~Gy}$, ar.u one dog at $25 \mathrm{ppm}$ and 27 Gy have also been irradiated.

Pharmacokinetics: No additional dogs have been infused.

The latest changes in the animal whart data from Project 2, Task 1 Large Animal Studies are summarized in Appendix $A$.

Task 2: Pituitary Tumor Treatment Evaluation Study

Experiments are continuing at Oregon Health Sciences University (OHSU) to evaluate the stimulation of AtT-2O and $\mathrm{GH}-3$ pituitary tumor cells invitro for the ultimate evaluation of the effect of neutron exposure on these cells in the absence and presence of the corticotropin releasing factor (CRF) and the growth hormone releasing hormone (GHR$\mathrm{H})$-carborane conjugates. The cell stimulation and response parameters are being defined for future reactor experiments at Oregon State University (ORSU).

$B L A B / C$ rnice, inoculated with "purified" preparation of CRF receptor continue to produce antibodies against the receptor moiety. Experiments are pianned to harvest mouse spleens and fuse the spleen cells with mouse myeloma cells to produce monoclonal antibodies.

OHSU researchers also plan to obtain fresh bovine and/or porcine pituitaries from local abattoirs in an attempt to obtain large numbers of fresh, normal, mammalian pituitary cells for the above experiments.
The Research Endocrine Laboratory at the ORSU reactor facility is being completed. More than half of the equipment ordered has been delivered to the facility and pilot experiments using pituitary cells are planned to begin soon.

ORSU reactor facility staff continue to define parameters required for planned pitultary cell irradiations. Thermoluminescent dosimeter (TLD700) measurements were carried out in lead cubes of various thickness to determine if the gamma field can be sufficiently suppressed in the cell exposure chamber. One-quarter to one-half inch thick lead shielding was placed around the sample tubes (in addition to the $10-\mathrm{crn}$ lead block placed in the proximal stringer window) and compared to results with no lead. At a distance of $12.2 \mathrm{~cm}$ from the inner end of the thermal column, the gamma was decreased by approximately $20 \%$. Tin and copper shielding will be evaluated to minimize any effect of lead-derived gamma source.

Task 3: Physiological Response Evaluation and Interdiction

The contract with the University of Rochester is not yet finalized.

Project 3: Human Pharmacokinetics

On August 27, 1991, the UofU Boron Project Interest Group held its inaugural meeting. After individual introductions and statements of interest in the boron MR pharmacokinetics/neutron capture therapy project, the tasks under the INEL/DOEfunded subcontract were outlined. The overarching goal is to validate the applicability of the boron MR technique by quantitation and distribution measurements in the canine brain. First, hardware developed by Ken Bradshaw (INEL) and Jeff Thomas (an Associated Western Universities student) will be tested in the GE Signa" imager. Subsequently, ${ }^{11} \mathrm{~B}$ NMR spectral and imaging data will be collected on normal dogs and those harboring intracranial neoplasms using BSH. These data will be compared with excorporal analysis of tissue obtained via stereotactic necropsy, as well as online blood sampling. The possibility of an eventual transfer to humans was also discussed. 
Dr. M. Peter Hellbrun, Chief of Neurosurgery, suggested considering the C6 canine glioma developed at the University of Maryland for the sake of reproducibility. Supportive views were expressed. Agreement was reached that this was a desirable direction to pursue.

Some discussion was raisot about "third generation" boronated compounds (i.e., low density lipoproteins (LDLs)) containing sequestcied boronated elaidic acid. These LDLs may have much better tumor absorption, but are as yet unavailable for large animal studies.

UofU researchers continue the interim evaluation of the "'B NMR irnaging and spectroscopy methods on canine models. As reported in detail in Project 1 , Task 5, two dog studies have been completed, including ${ }^{11} \mathrm{~B}$ spectroscopic and imaging data with venous blood sampling during infusion, distribution, and elimination of $\mathrm{BSH}$. Tissue necronsies were also performed.

\section{Project 4: Drug interaction and Toxicity}

No reportable progress.

\section{B. MELANOMA RESEARCH}

Project 1: Boron Localization Screening

Screening of Liposome BNCT Compounds: As reported last month, 48 tumor-bearing $B_{6} D_{2} F_{1}$ (BDF) mice were inoculated intravenously into the tail vein with $200 \mu \mathrm{L}$. of the liposome compound $\left(\mathrm{Na}_{4} \mathrm{~B}_{2}\right.$ ${ }_{0} \mathrm{H}_{17} \mathrm{OH}$ in $9 \%$ lactose, $5 \mathrm{mM}$ phosphate buffer) received from UCL.A researchers. Control mice were inoculated with $200 \mu \mathrm{L}$ of saline solution. Tissues were sampled at 0 (control), 6, 12, 18, ?.4, and 36 hours postinnoculation (eight mice per time point), frozen, and sent to INEL. for boron analysis. Sampled tissues include tumor, liver, spleen, brain, kidney, skin, skeletal muscle, and whole blood.

Praliminary results on four mice/sample period and selected tissues (four out of eight sampled tissues) are averaged and shown in Table III. Boron levels are highest in the liver, as would be expected, as the liver is the primary site of detoxification, although levels in the liver approximate blood levels. Levels in the lung peak at $10 \mathrm{ppm}$. Levels of boron in tumor and liver tissue appear to peak at 12 hours postinnoculation of the liposomal compound. Blood and splenic levels peak at 18 and 6 hours, respectively. Loss of boron from tumor tissue appears to

Table III. Boron Levels (ppm) in Tissues Excised at Indicated Times From Tumor-Bearing Mice Follow. ing Intravenous Delivery of Liposomal Boron Compound at $\mathrm{t}=0$.

\begin{tabular}{|c|c|c|c|c|c|}
\hline \multirow{2}{*}{ Hour } & \multirow{2}{*}{$\begin{array}{c}\text { Parent } \\
\text { Liposome } \\
\text { Compound }\end{array}$} & \multicolumn{4}{|c|}{ Tissue } \\
\cline { 3 - 6 } & Tumor & Blood & Liver & Spleen \\
\hline 0 & 898 & 0.724 & 0.797 & 0.511 & 1.000 \\
\hline 6 & & 7.813 & $\cdots$ & 27.481 & 21.636 \\
\hline 12 & & 10.369 & 25.583 & 31.993 & 16.435 \\
\hline 18 & & 8.655 & 26.968 & 23.219 & 10.939 \\
\hline 24 & & 7.503 & 17.017 & 24.692 & 17.123 \\
\hline 36 & & 5.165 & 7.551 & 10.010 & 6.035 \\
\hline
\end{tabular}


be slower compared to loss from other tissues. Further analyses of the data are pending uritil the remainder of the data is received. At that time, statistical significances will bo desermined and final interpretations and experimental modifications li.e., de reasing the number of mice per time point, adding a 48-hour sampling point, udministering the drug in a split dose) will be made. Preparations are underway to complete two liposomal delivery assays per month.

Project 2: Biodistribution, Pharmacology, and Toxicity of Boron Delivery Agents

\section{Task 1: BPA/Molecusol/DEA Availability Study}

Specific pathogen-free, female mice at 6-8 weeks of age have been reordered and are scheduled to arrive at WSU October 3, 1991. Upon receipt, they will be set up and the biodistribution of BPA in mice fed a normal diet and a diet low in tyrosine and phenylalanine will be repeated.

Analysis of Physiological Data: ISU researchers still have a backlog of physiological data acquired from previous canine experiments. Analysis of this data, however, should soon be possible. The Run Technologies DATAPAC-II data analysis software program has been installed on an 80486-based computer. The files this program will analyze are on the order of $50 \mathrm{Mb}$ and, as with any new, complex software package, numerous unexpected "bugs" have been found. Researchers are gradually working through this problems and hope to have the data analysis capability fully functional within the next few weeks. The current problem is that while DATAPAC-1I is now functional, a bug has surfaced in the data transfer system. All of the analog data has been digitized (i.e., blood pressure and respira. tory ratel and stored on magnetic tape via an

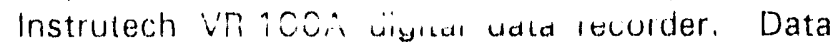
from the magnetic tape can then be transferred to the DATAPAC-II software via a VR-111 interface device. While the VR-111 searns to interface correctly with the VR-100A, the DATAPAC-11 software is not reading the transferred data consistently. Instrutech and Run Technologies technical support have suggested several possible causes.
ISU researchers are currently inserting an intermediate data conversion step (converting the TPE files to FETCHEX files) to determine if is this will correct the problem.

Kinetic Analysis of Boron in Physiological Samples: INEL has completed the boron analysis of all dog plasma, serum, and urine samples. Sufficient data are now available to begin pharmacokinetic modeling of the data.

Rat Bioavailability Studies: A protocol for these studies has been finalized and initial experimentation validating the key methodologies is now complete. These studies will investigate the pharmacokinetics of BPA formulations in male, Sprague-Dawley rats to determine if: (1) initial pharmacokinetic experiments can feasibly be conducted in rats, (2) the pharmacokinetic profiles in rats mimic the pharmacokinetic profiles in dogs, (3) unanticipated side effects noted in dogs are also observed in the rat model, and (4) novel drug delivery systems can increase levels of drug circulating in the blood and the bioavilability of the drug.

Analytical Methods Development: ISU researchers have discontinued the use of the Supelco LC-HISEP column for BPA analysis because of a lack of sensitivity and poor column life expectancy under current analytical conditions. The Nucleosil C-18 column is being evaluated as a replacement. Analytical conditions allow successful quantitation of BPA concentrations in aqueous formulations and this technology is currently being used to evaluate the stability of BPA formulations prepared for rat bioavailability studies. Isolation of BPA from physiological samples (plasrra, serum, urine) has proven to be more difficult than initially envisioned. Current methodologies permit reproducible recovery of BPA from plasma (albeit at a $40-50 \%$ recovery rate), but coelution of variable quantities of an unknown, endogenous substance is preventing an accurate determination of BPA in blood samples. In collaboration with scientists at Analytichem International, new solid phase extraction technology will be evaluated as a means of eliminating the interfering substance. Three new types of extraction columns are being evaluated. The first is a C.8 column, encapped with a cation exchanger, benzene sulfonic acid. In theory, adjusting BPA to an acidic $\mathrm{pH}$ should give BPA sufficient positive charge 
to be retained on the column. BPA will then be eluted off the column with an organic solvent containing a competing anion (i.e., chloroform/ammonia). Preliminary results with this type of column indicate no column retention of BPA at $\mathrm{pH}$ 2.0. More Acidic $\mathrm{pH}$ conditions are being examined as the $\mathrm{pKa}$, for BPA has betn reported as 2.46. The second type of column was selected as a result of literature reports indicating that phenylboronic acid compounds bind to cis-diols. Addition of base to BPA-containing solutions should allow BPA to be retained on the diol column, whil the interfering substance may pass through. BPA could then be eluted from the column by using a strong acid (i.e., O.1N HC1). The third approach is to use a $\mathrm{C}-8$ column, endcapped with an anion exchanger (i.e., a quaternary amine). In theory, this column will bind hydrophobic and negatively-charged compounds. By adjusting BPA-containing solutions to a neutral Ph, BPA should bind to this column while competing substances pass through.

\section{Task 2: Toxicological Evaluation of BPA}

Most of the instrumentation critical to this task has arrived at ISU, but key instrumentation is still missing. The initial experimental goal has been to evaluate the technology availab!e for measuring cardiac flow. Evaluation of five cardiac flowmeters that utilize one of three physical principles has begun. Two units operate by electromagnetic flow detection. The analyzer probe is implanted around the lumen of the blood vessel to be measured and the probe then creates an electromagnetic field across the lumen of the vessel. Blood flow through the lumen causes changes in the electromagnetic field and the magnitude of these changes provides a measure of the absolute blood flow through the vessel. The Carolina square-wave, electromagnetic flowmeter was deemed unacceptable because flow values were critically dependent on hematocrit concentration and accurate readings required hematocrit determinations every few minutes to verify alterations in hematocrit were not biasing the data. Intravenous injection of $1 \mathrm{~mL}$ of saline changed hematocrit levels enough that recalibration of the probe (and its concomitant hematocrit determination) was necessary to ensure accurate measurement of cardiac flow. The Scala flowmeter operated on the same principle as the Carolina unit, but did not allow compensation for changes in hematocrit. Thus, the Scala system was easier to use than the Carolina system, but was also less accurate. This unit was also returned to the manufacturer.

Two other flowmeters, Triton Technologies and Crystal Biotech, utilize doppler flow sensing technology. With these systems, minute probes implanted on the wall of the blood vessel generate a beam of ultrasound through the lumen of the vessel. Reflections of this beam are sensed by the probes and, since the extent of reflection is related to the speed of blood flow, these reflections are used to calculate velocity through the lumen (measured values are expressed as $\mathrm{cm} / \mathrm{sec}$ ). After using this system for a while, it was realized that it measures only velocity and not absolute flow through a vessel. While the relationship between absolute flow and velocity is linear as long as the vessel diameter remains constant, most vessels have the potential to constrict or dilate over time as part of the reflex response for maintaining a stable blood pressure. Thus, both of these units were judged to be unacceptable for Program purposes and are being returned to their manufacturers.

The most promising flowmeter, Transonic TD-106, utilizes transit time, ultrasound flow measurements. The probe of this unit consists of two ultrasonic transducers and a fixed acoustic reflector bracket. The arrangement allows the unit to measure, not only the velocity of the blood through the vessel, but also the change in vessel diameter. By integrating the two measurements, the analyzer unit can calculate the absolute volume flow. The primary disadvantage of this system is that the relatively large probe requires significantly greater surgical skills during the implantation procedure. All factors considered, the conclusion is that the Transonic system is best-suited to Program requirements and needs and this unit will be purchased in the near future. 


\section{Project 3: Large Animal Model Studies}

Potential patients for large animal studies continue to be identified. There was no other activity to report this month.

Project 4: Melanoma Detection and Boron Quantification by Scintigraphy

Uptake and Distribution of Radiolabelled Boron Compounds: A pilot study investigating the in-vivo biodistribution of a ${ }^{126} /$-radiolabelled borovaline analog in turnor-bearing mice has been planned and will begin the first week of October 1991. Fifteen (15) mice will be injected subcutaneously with BL6 melanoma on October 3, 1991. When the tumor reaches approximately $1.0 \mathrm{~cm}$ in diameter (approximately two weeks after tumor injection - October 17, 1991), the mice will be injected interperitoneally with the radiolabelled boron compound. This borovatine compound will be synthesized in the College of Pharmacy at WSU and radioactively tagged with ${ }^{12.5}$ in the laboratory one week prior to compound injection. Three mice per time point vill be sacrificed at $2,6,12,24$, and 48 hours postinjection. Tissues will be excised and radioactivity in these tissues will be measured in a gamma scintillation counter. Tissues to be sampled include tumor, brain, lung, liver, kidney and adrenals, intestines, whole blood and plasma, heart, thymus, skin with hair, and gastrocnemius muscle. Data collected from this experiment will provide experience in labelling boronated compounds and should indicate feasibility and potential directions for future experiments of this type.

Project 5: Boronated Low Density Lipoproteins and Amino Acid Development and Evaluation

UCSF researchers have made significant progress in finding an alternative method of isolating human
LDL from plasma. An alternative to the lengthy, time-consurning process of density gradient ultracentrifugation has been sought to increase the amount of material available for boron loading and subsequent in-vitro and in-vivo distribution studies. In conjunction with a group at Per Septive Biosystems (Cambridge, MA), a new method has been developed using HPLC perfusion chromatography. This method is based on the unique morphology of a proprietary class of particles. These particles contain both transecting and diffusive pores that, in combination, provide extremely rapid mass transport. This makes possible both high resolution and high capacity at speeds 10-100 times faster than HPLC with conventional packings.

The results are shown in Figures $4 a, 4 b$, and $4 c$. Figure $4 a$ shows the chromatogram following a $1.5 \cdot \mathrm{mL}$ injection of plasma from a healthy volunteer researcher directly only the column. The column used was a $10 \times 10 \mathrm{~mm}$ Poros $\mathrm{HS} / \mathrm{M}$ strong cation exchange column with a total column volume of approximately $8 \mathrm{mLs}$. A $23.5-\mathrm{mL}$. minute flowrate of $\mathrm{pH} 6.1$ buffer was used and the column effluent was monitored at $280 \mathrm{~nm}$. The LDL 12.60 minute retention time) is clearly separated from the VLDL (2.32 minutes) and other plasma components. Figures $4 \mathrm{~b}$ and $4 \mathrm{c}$ represent $1-\mathrm{mL}$ injections of standard solutions of LDL (Figure 5) and V/LDL (Figure 6). As vet, the HDL peak has not been identified, but it may be at 3.18 minutes. Obviously, this preparative separation needs to be optimized, which is likely possible using a shallower gradient, providing longer elution times, and a 16 $\mathrm{mm}$ diameter column that will give higher efficiency. Such a column has been ordered and it is hoped to have it operational by mid-October 1991. It still remains to confirm the viability of the chromatographed LDL by PAGE gel electrophoresis, but, if this proceeds as expected, a powerful new tool for isolating large amounts of LDL will have been identified. 

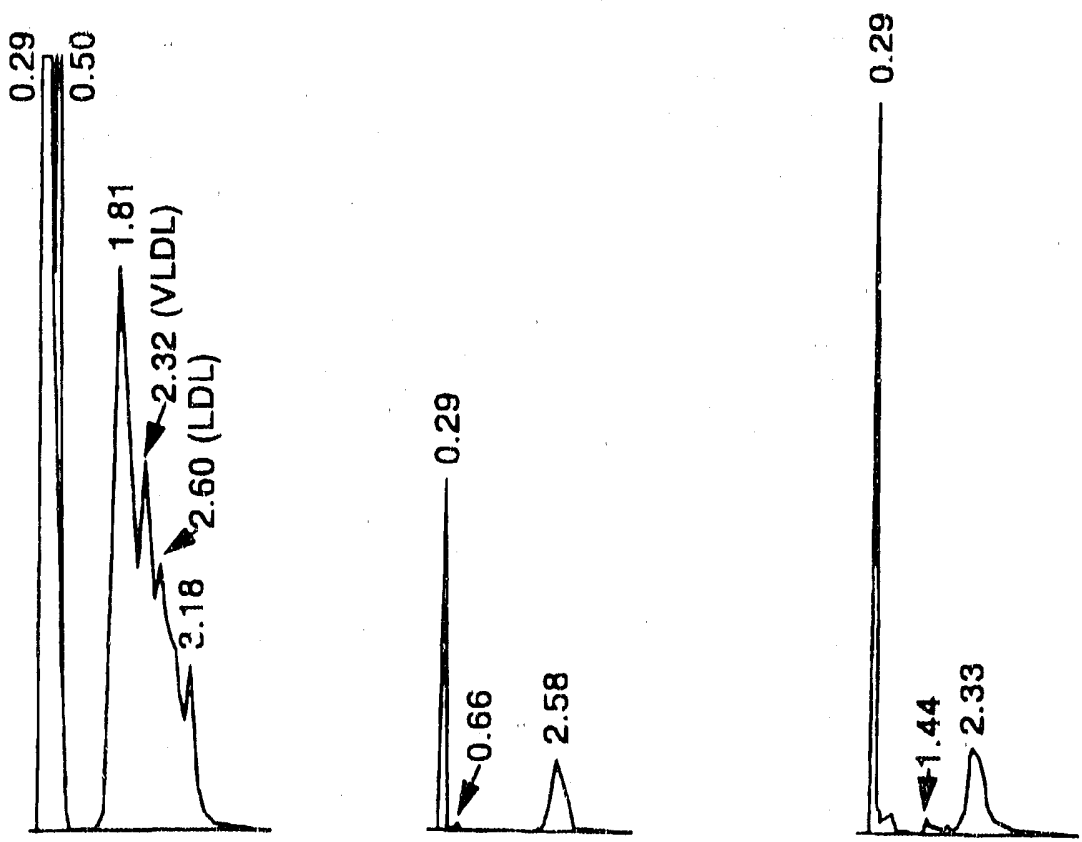

Figures $4 a, 4 b$, and $4 c$.

Project 6: Boronated Liposome Development and Evaluation

UCLA researchers have encapsulated sufficient amounts of $\mathrm{K}_{4} \mathrm{~B}_{20} \mathrm{H}_{17} \mathrm{OH} \cdot 3 \mathrm{H}_{2} \mathrm{O}$ into liposomes for murine experiments using a melanorna tumor line (WSU researchers) and the EMT6 tumor line (Vestar, Inc.) The melanoma experiments have been completed and partial boron analyses have been obtained. Based on these preliminary data, the hydrolysis product of $\left[i-\mathrm{B}_{20} \mathrm{H}_{18}\right]^{2 \cdot}$ does not appear to be as effective as the parent $\left[i-\mathrm{B}_{20} \mathrm{H}_{18}\right]^{2}$. It is not yet clear whether this is a function of the boron compound used or the alteration of the tumor model used. A murine experiment with the EMT6 tumor line using $\mathrm{K}_{4} \mathrm{~B}_{20} \mathrm{H}_{17} \mathrm{OH} \cdot 3 \mathrm{H}_{2} \mathrm{O}$ liposomes is being arranged with Vestar.

Development of the synthesis and chemistry of new boron species as candidates for liposomal delivery is continuing. The amine derivative of $\left[n-\mathrm{B}_{20} \mathrm{H}_{18}\right]^{2} ;,\left[\mathrm{B}_{20} \mathrm{H}_{17} \mathrm{NH}_{3}\right]^{3 \cdot}$, has been synthesized and is in preparation for liposome encapsulation.
Expansion of this synthetic route to obtain the benzylamine $\left[\mathrm{B}_{20} \mathrm{H}_{1}, \mathrm{NH}_{2}\left(\mathrm{C}_{6} \mathrm{H}_{5}\right)\right]^{3 \cdot}$ and octylamine $\left[\mathrm{B}_{20} \mathrm{H}_{17} \mathrm{NH}_{2}\left(\mathrm{CH}_{2}\right)_{7} \mathrm{CH}_{3}\right]^{3 .}$ derivatives appears to be successful. Current efforts in this area are centered on purifying and characterizing these species. Investigations of the chemistry of $\left[\mathrm{B}_{10} \mathrm{H}_{8} \mathrm{CO}\right]^{1}$, $\left[\mathrm{B}_{10} \mathrm{H}_{9} \mathrm{CO}_{2} \mathrm{H}\right]^{2-}$, and $\left[\mathrm{B}_{10} \mathrm{H}_{9} \mathrm{NCO}^{2 \cdot}\right.$ are also continuing. Reduction of the carbonyl compound $\left[\mathrm{B}_{10} \mathrm{H}_{8} \mathrm{C}\right.$ O) ${ }^{1 .}$ with lithium borohydride appears to have produced the new species $\left[\mathrm{B}_{10} \mathrm{H}_{8} \mathrm{CH}_{2} \mathrm{OH}\right]^{2}$, whose characterization is in progress.

\section{ADMINIS:RATION}

Contracts/Subcontracts: The subcontract with Stanford University was awarded September 6, 1991. The subcontract with WSII has been extended, to allow continuity of the woik as the fiscal year boundary is crossed. No new money was committed for WSU. 
Budget: Internal (EG\&G Idaho, Inc.) BNCT research redirection was finalized and the recommendation consensus was conveyed to DOE-ER by DOE-ID and $E G \& G$.

The BNCT Research Program and PBF will begin the new fiscal year without knowledge of the FY-92 budget. Both areas will continue at the same level of effort in the new fiscal year as they are presently spending. PBF will continue with the matrix support in planning for the LOCA pipe removal and compliance modifications that were begin in FY.91.

Presentations: Merle Griebenow (INEL) summarized the INEL BNCT Program progress for Congressman Stallings and his legislative assistant, Cary Jones; for Nils Johnson from Senator Craig's staff; and for two of Senator Symms' staff.

Boron Compound: The last shipment of the enriched BSH compound from Callery Chemical was found to contain about $31 \% \quad \mathrm{~B}_{12} \mathrm{H}_{12}$, with the remaining compound being $\mathrm{BSH}$ (see Project 1, Task 2). Callery has requested the return of this compound. After discussions with INEL chemists, it was decided to utilize some of the compound on four dose-tolerance dogs now at BNL awaiting irradiation. The $\mathrm{B}_{12} \mathrm{H}_{12}$ will not preferentially accumulate in tumors, but as these tests are dose tolerance, the total boron will be the same as in blood. The only possible change could be a faster elimination rate from the body.

BNL/BMRR: BNL was requested to: (1) accelerate DCP availability, (2) include an INEL analyst in factory DCP training to facilitate INEL transfer of the ultrasensitive methylborate analyses to $B N L$ in support of INEL irradiations at BMRR, and (3) hire a fulltime dosimetrist so INEL does not need to send two dosimetrists to BNL for each dog irradiation. BNL and DOE-HO have tentatively agreed to all actions, as soon as the FY.92 budget is firm.

Publications: Five (5) papers were submitted to DOE for approval and clearance prior to submission for publication. They are:

1. Floyd J. Wheeler, "Dose Calculations Based on Image Reconstructions," to be submitted to the Proceedings of the Intema tonal Workstiop ard Plenary Mesting, Towards Clinical Trials of Glioma with BNCT held at Petten, 'The Netherlands, September 18-20, 1991.

2. Floyd J. Wheeler and Daniel E. Wessol, "Methods for Creating and Using Free Form Geometries in Monte Carlo Particle Transport, " to be submitted to Nuclear Science and Engineering Journal.

3. Susan L. Kraft, Patrick R. Gavin, William F. Bauer, David L. Miller, and Merle L. Griebenow, "Biodistribution of Boron in Dogs with Spontaneous Intracranial Tumors Following Borocaptate Sodium Administration - Part I: Tumor Boron Concentrations," to be submitted to Radiation Research Journal.

4. Susan L. Kraft, Patrick R. Gavin, William F. Bauer, David L. Miller, and Merle L. Griebenow, "Biodistribution of Boron in Dogs with Spontaneous Intracranial Tumors Folloving Borocaptate Sodium Administration - Part II: Boron Concentrations of Normal Canine Tissues," to be submitted to Radiation Research Journal.

5. Susan L. Kraft, Patrick R. Gavin, Constance E. DeHaan, Charles W. Leathers, Williarn F. Bauer, David L. Miller, and Ronald V. Dorn III, "Borocaptate Sodium: A Potential Boron Delivery Compound for Boron Neutron Capture Therapy Evaluated in Dogs with Spontaneous Intracrani" al Tumors," to be submitted to the Proceedings of the National Academy of Sciences.

Meetings: Merle Griebenow, Floyd J. Wheeler (INEL), Dr. Ronald V. Dorn III (INEL/MSTI), and Dr. Patrick R. Gavin (WSU/Petten) represented the INEL BNCT Program at the International Workshop and Plenary Meeting, "Towards Clinical Trials of Glioma with BNCT," sponsored by the European Collaboration on BNCT at Petten, The Netherlands, September 18-20, 1991. Floyd Wheeler was a guest speaker and gave an oral presentation entitled, "Dose Calculations Based on Image Reconstructions." Dr. Dorn gave an oral presentation entitled, "The INEL BNCT Program Directions with Respect to Clinical Trials of BNCT." Dr. Gavin, who is currently on sabbatical assignment at Petten, gave an oral presentation on "Large Animal Model Studies for BNCT," Drs. Gavin, Huiskamp, Co- 
derre, and Floyd Wheeler met to discuss microdosimetric considerations for Dr. Coderre's cell survival studies. It was agreed that it would be beneficial to perform calculations for these experiments to better understand the differences in cell survival for different cells and compounds. It was announced at the meeting that an agreement had been reached with Plenum Publishing to publish the transactions of the meeting; therefore, Floyd Wheeler has drafted a full paper of his oral presentation (see Publication No. 1 above).

\section{PBF TECHNICAL SUPPORT AND OPERATIONS}

\section{PBF Operations}

A DOE-ID Reactor Safety Appraisal was conducted the week of September 20, 1991. Recommendations from the 1990 appraisal were closed. An EG\&G Idaho, Inc. Performance Oversight and Assessment Surveillance was also conducted during the week of September 16-20, 1991, with EG\&G Health Physics personnel.

The following preventive maintenance items were completed: (1) continuous air monitors, (2) stack gas monitor, (3) chemical treatment pump, (4) emergency generator, (5) plant and auxiliary air compressor, (6) overhead 5/15 ton crane, (7) air conditioners, (8) relamping, (9) exhaust fans, and (10) waste gas exhaust fans.

Training conducted during the month corisisted of: (1) operations safety meeting (2) emergency brigade training, (3) emergency drill, (4) Personnel Security Assurance P: ogram training for personnel in sensitive positions, (5) experimental reactor operator support personnel duties and responsibilities initial training, and $(6)$ two training coordinators witnessed the annual emergency exercise at Prairie Island Nuclear Generating Station in Minnesota.

\section{PBF Technical Support}

The five-year inspection of the PBF canal permanent and temporary fuel storage racks was completed. The inspection included a visual inspection of the canal racks using an underwater television camera and a neutron interrogation of the racks to determine the condition of the cadmium poison. The neutron interrogation verified that the minimum required 0.002 inches of cadmium was present and estimated the total thickness of cadmium in the racks. No degradation of the canal rack structure or noison integrity was found. A final ieport summarizing the inspection results is being written.

The following activities are ongoing and will continue in the engineering and planning phases pending further direction from DOE:

1. Removal of the unused Loss-of-Coolant Accident (LOCA) piping and instrumentation from the annulus.

2. Requirements determination for the rewrite of the Final Safety Analysis Report.

3. Separation of the potable and raw water systems.

4. Replacement of the building temperature monitoring system.

5. Installation of the limit switches in the 5/15-ton crane.

6. Design of the reactor vessel weld mockup.

7. Initial investigations into PBF reactor fuel removal and storage.

8. Upgrade of the electrical service entrance to PBF Buildings 621 and 624 .

Weekly meetings are being held between the mechanical and electrical engineers and PBF Technical Support to ensure continuity of direction among participants. 


\section{APPENDIX A}

\section{LARGE ANIMAL MODEL STUDIES}

SUMMARY OF PATIENT DATA 

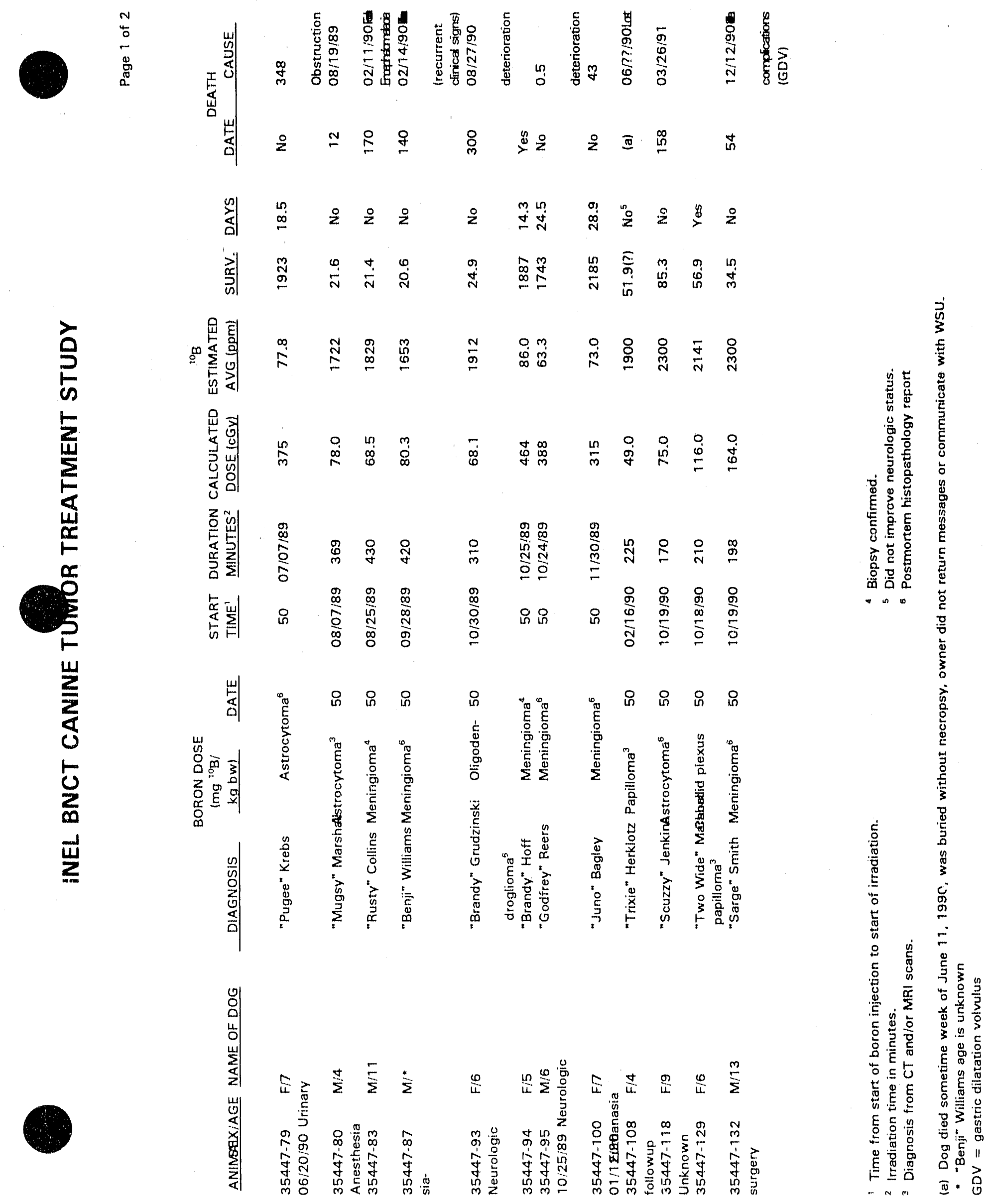


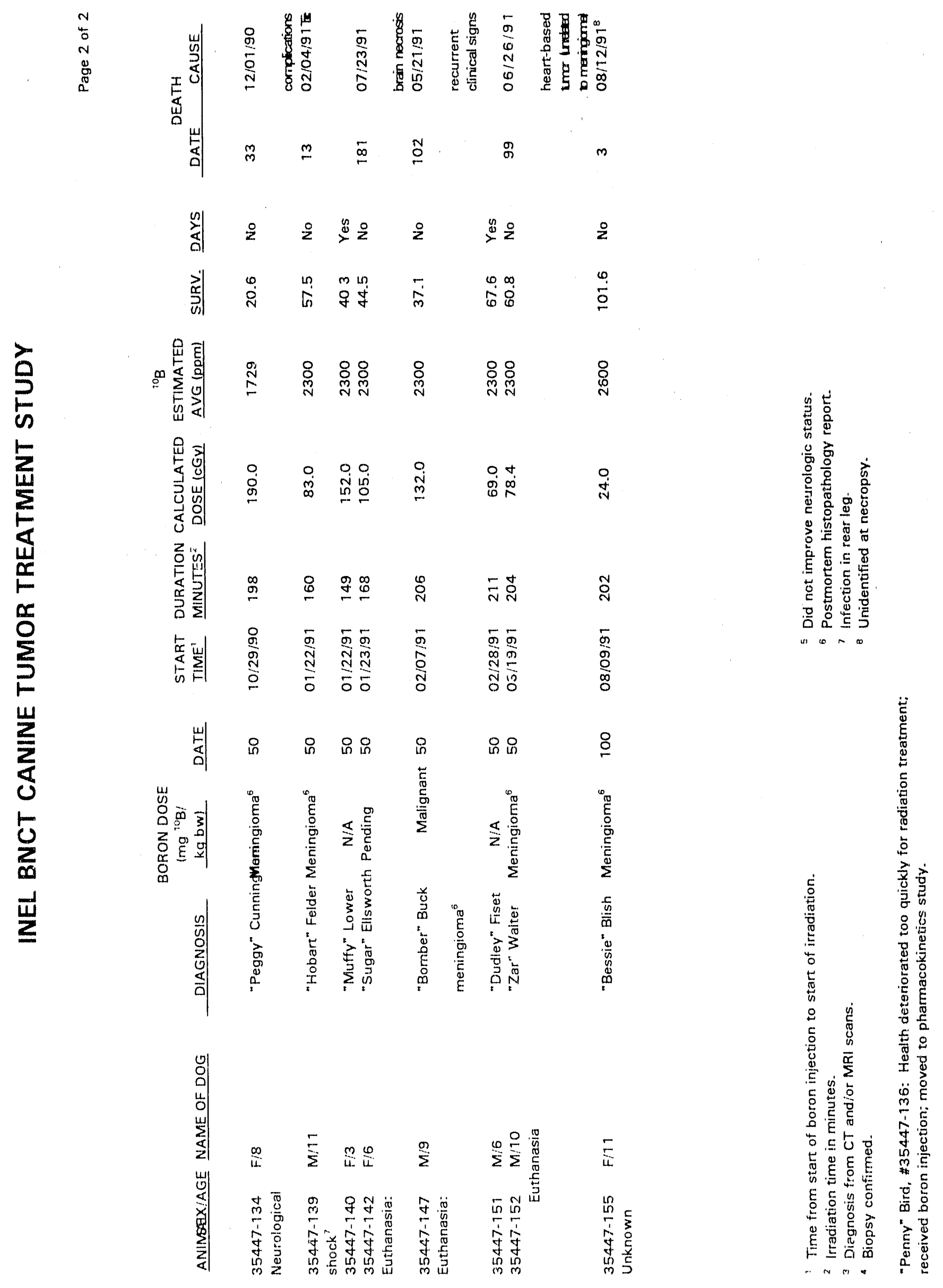




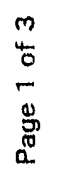

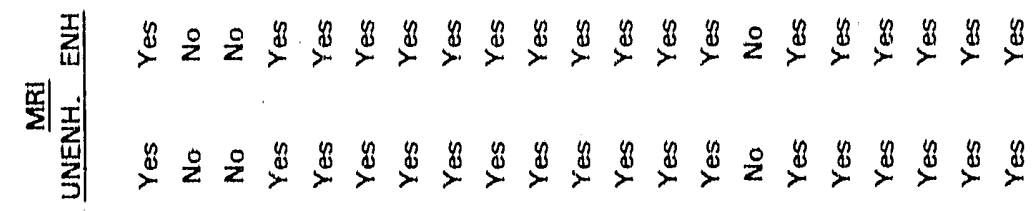

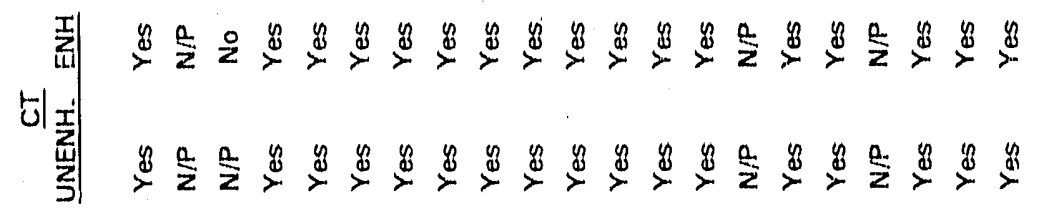

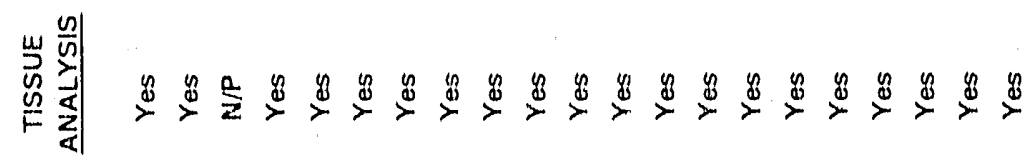

总

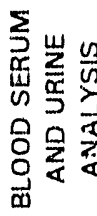

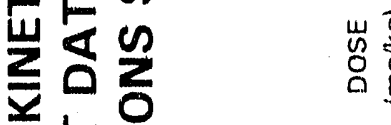

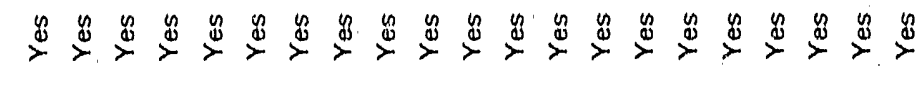

岕言 经

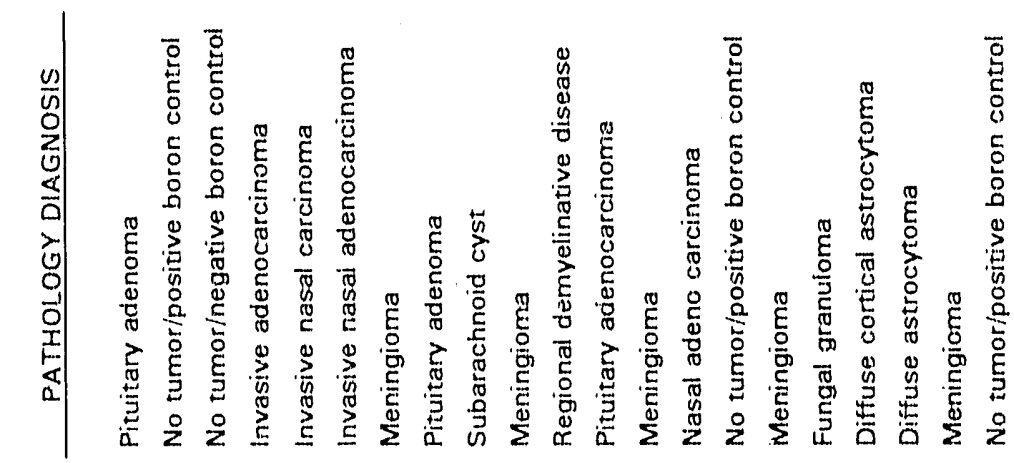

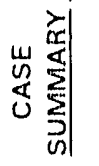

ע

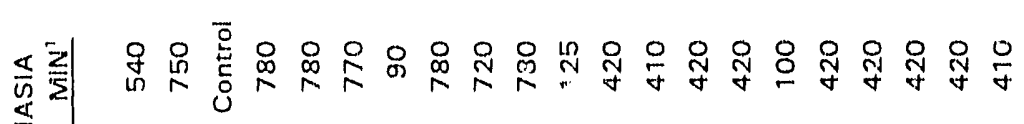
$\sum_{4}^{4}$

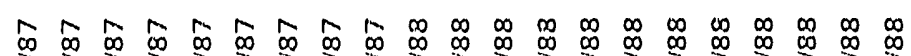

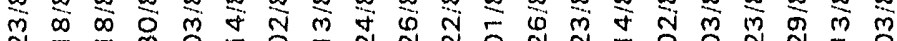

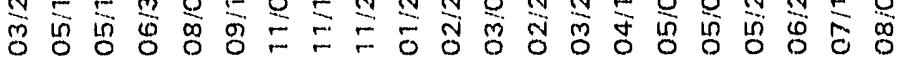

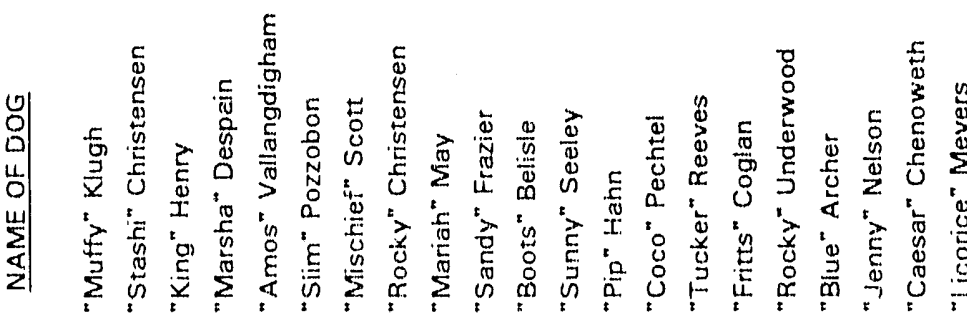

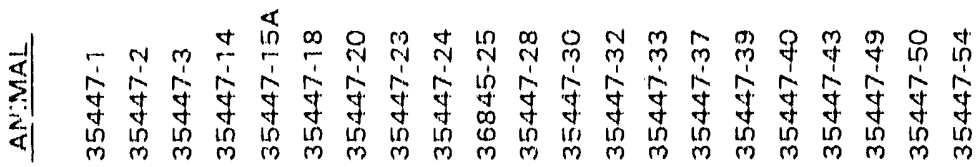

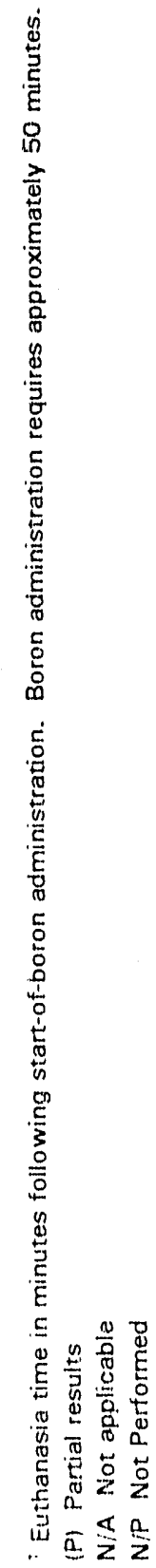




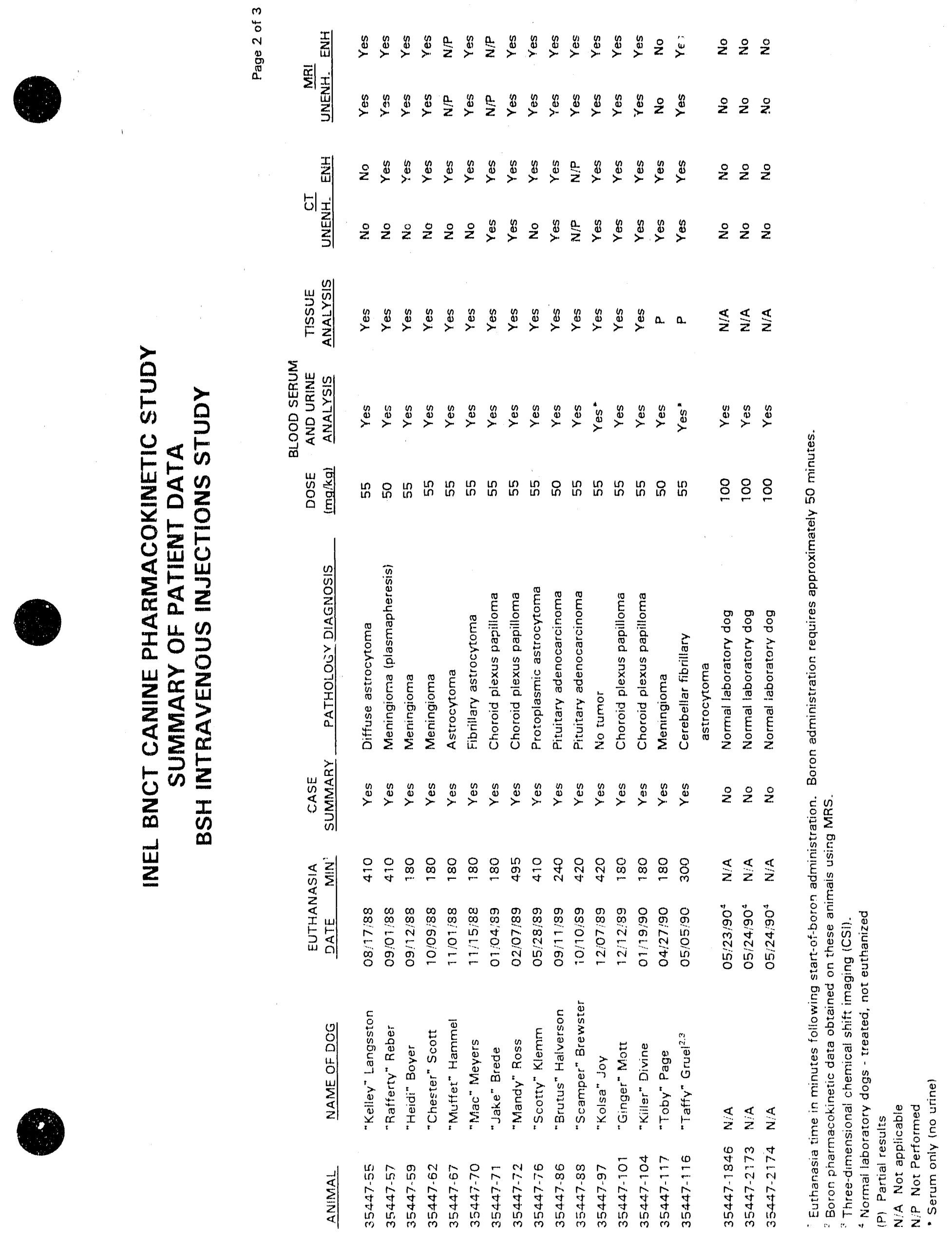



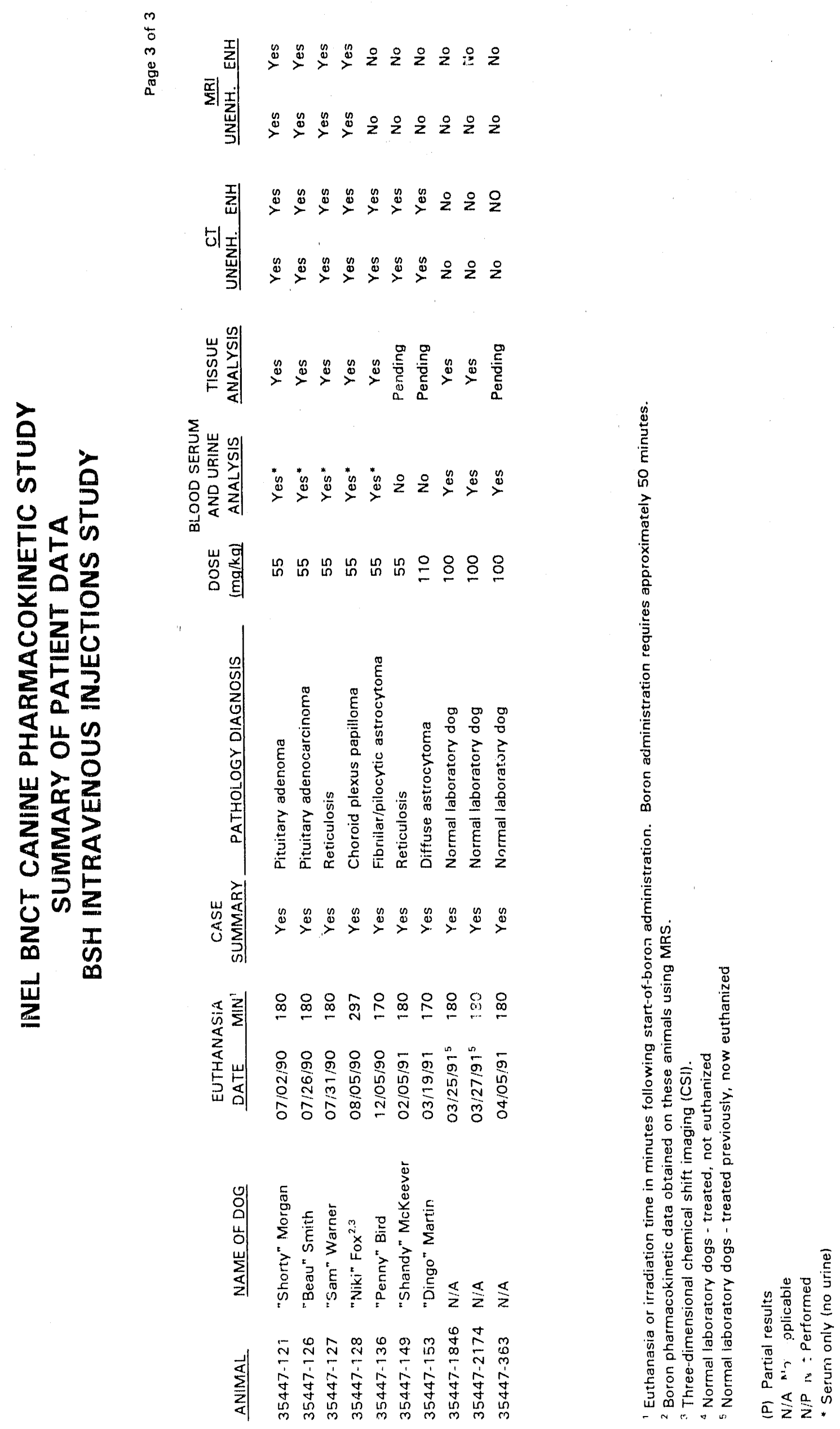


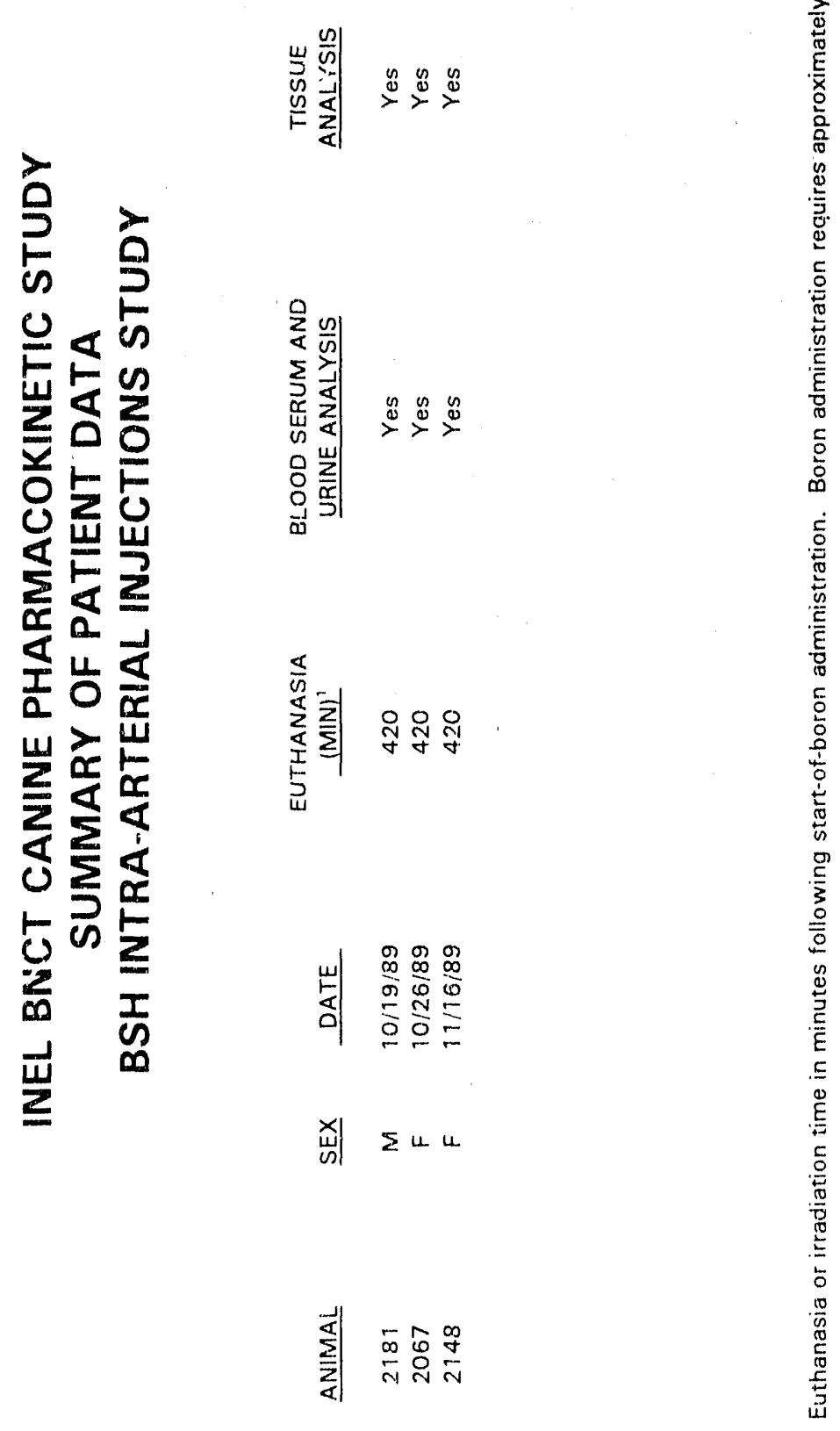


$\vdots$
$\stackrel{5}{0}$
$\frac{-}{0}$
0
0
0

工点

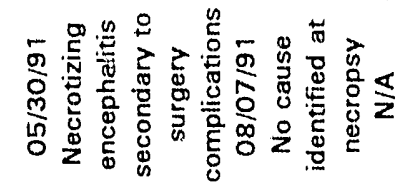

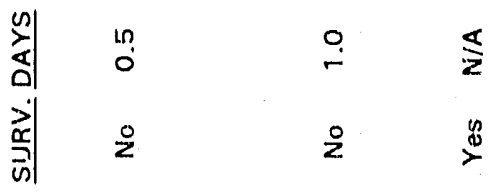

方

象高高

总矛

을

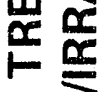

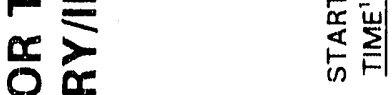

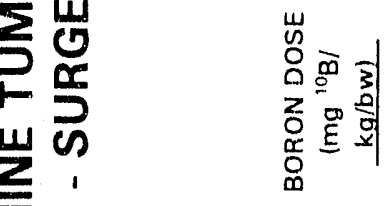

S嵌

这嵌

就兵

$\underline{\underline{z}}$

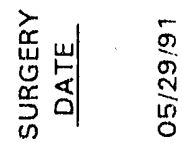

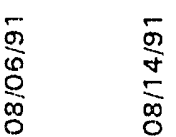

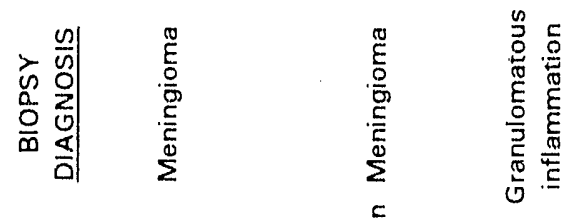

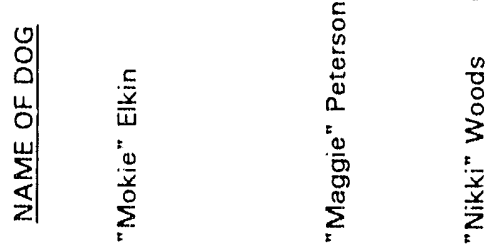

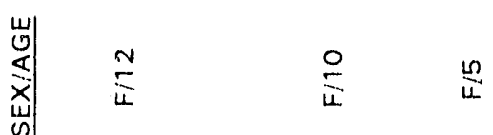

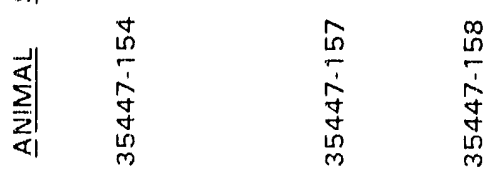

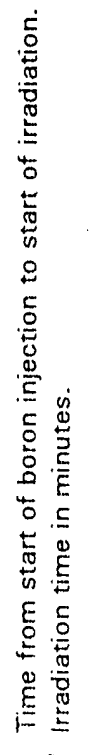




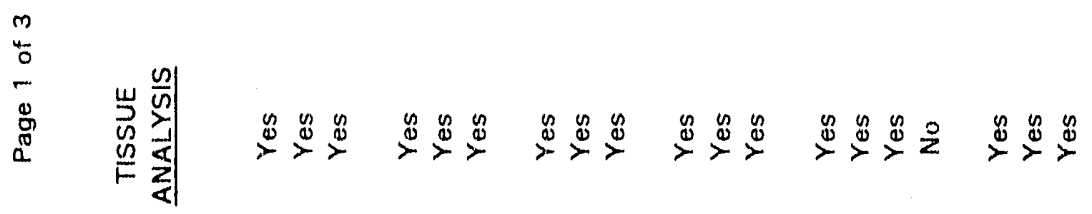

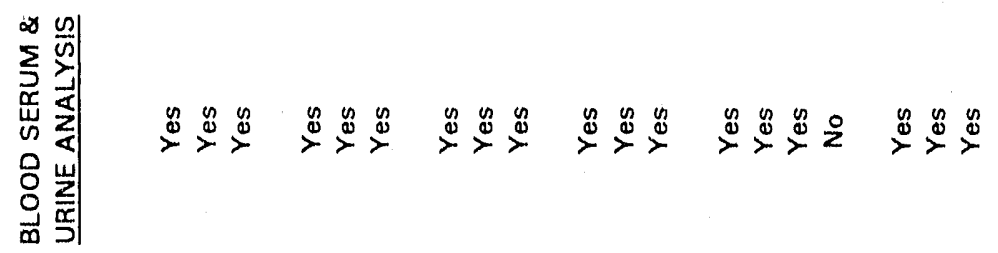

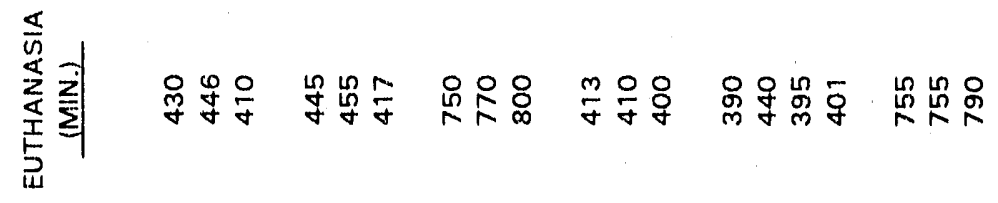
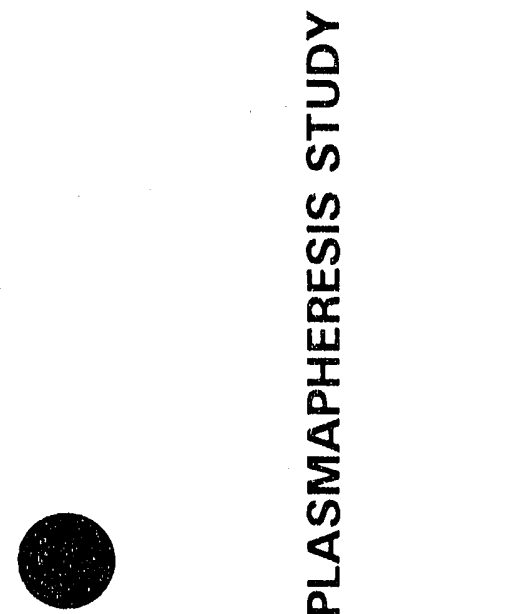

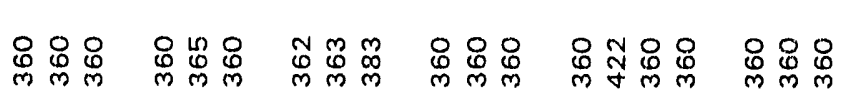

产

$\underline{\underline{Z}}$

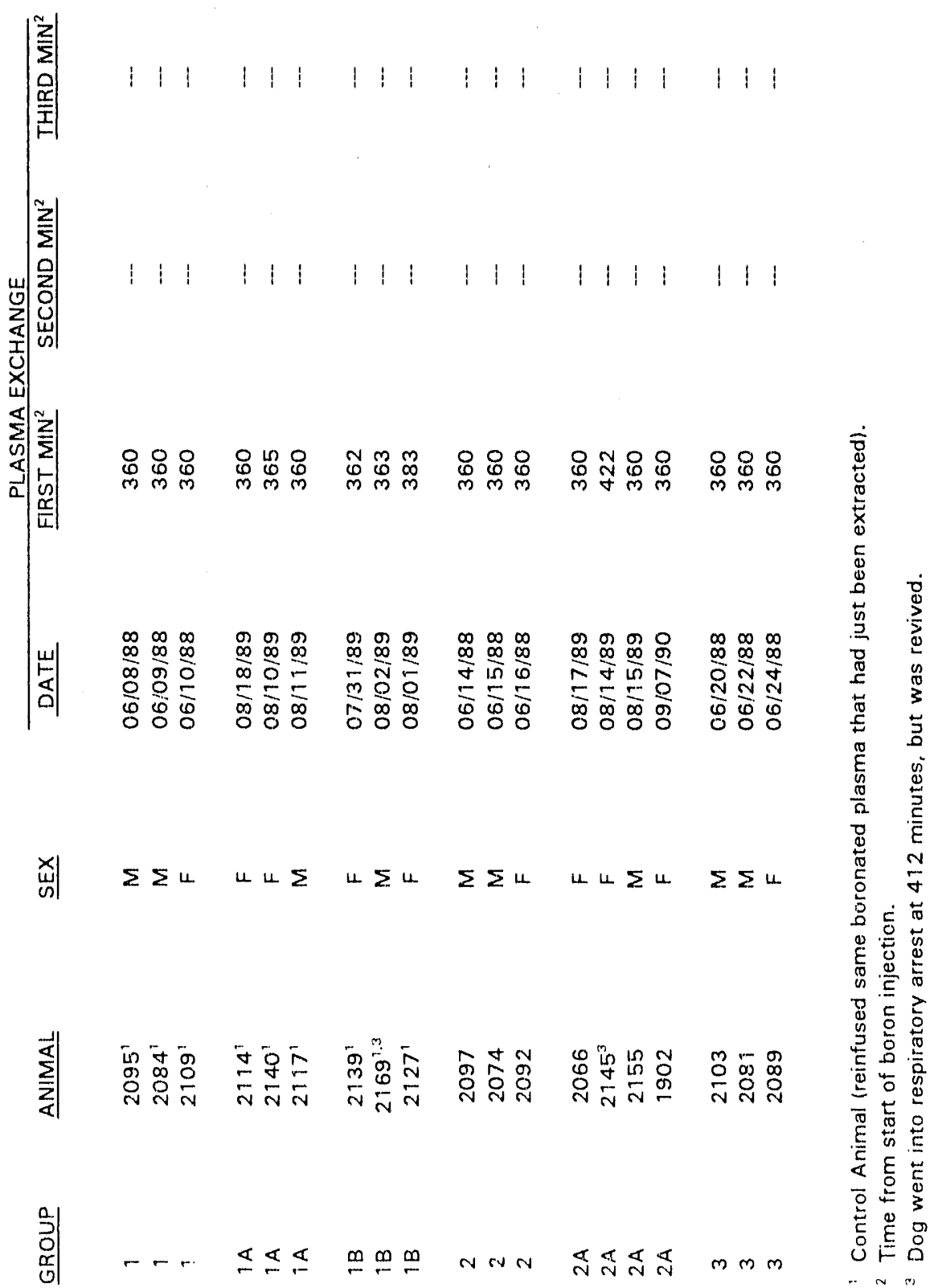




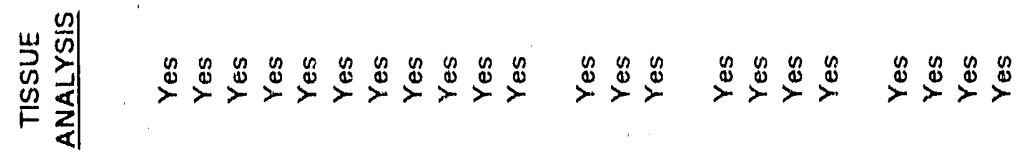
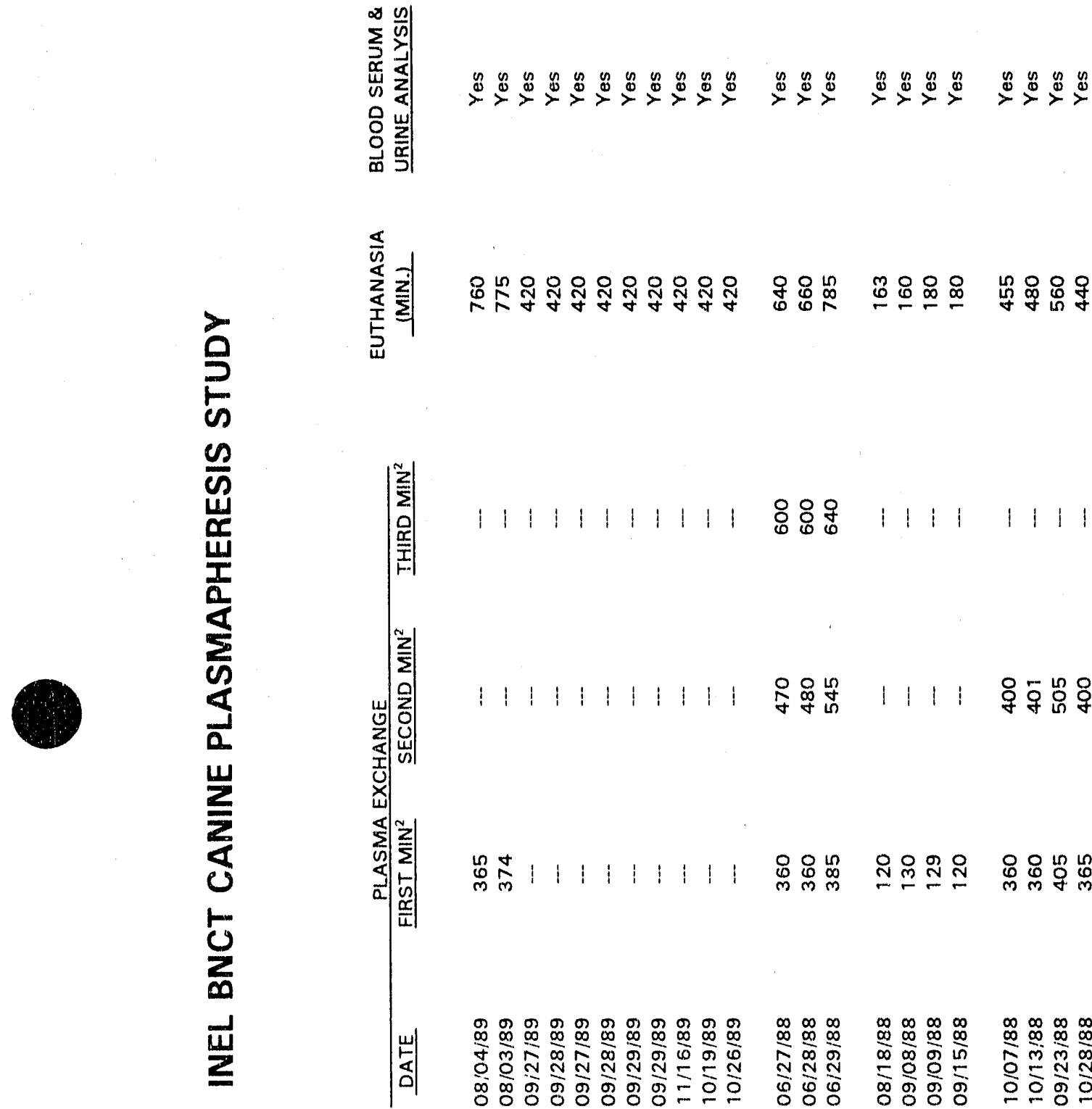

111111111118808081111111

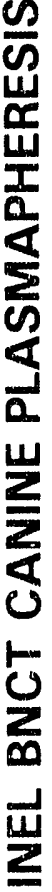

en

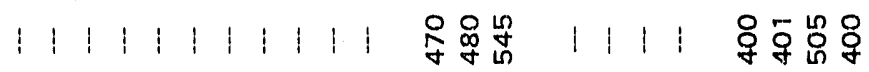

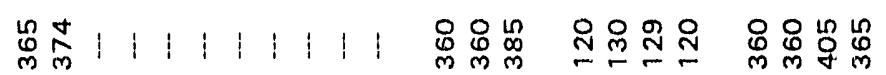

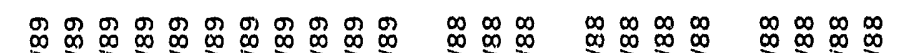

于

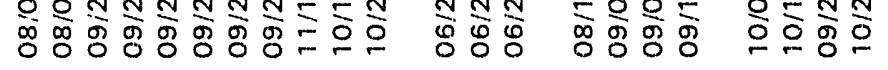

㜄

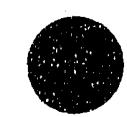

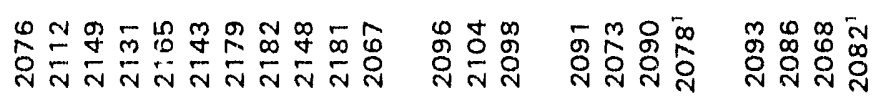

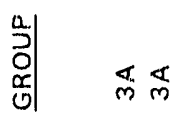

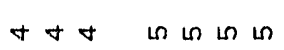

$\omega 000$

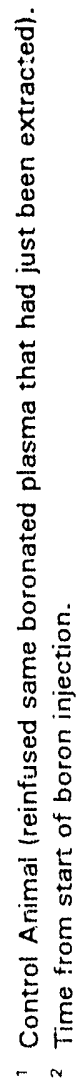




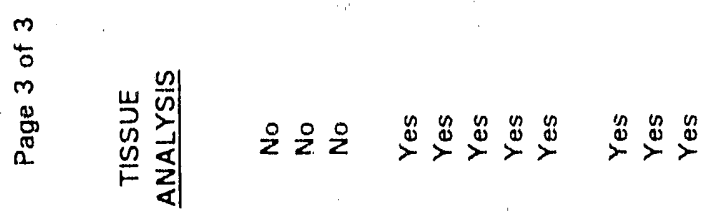

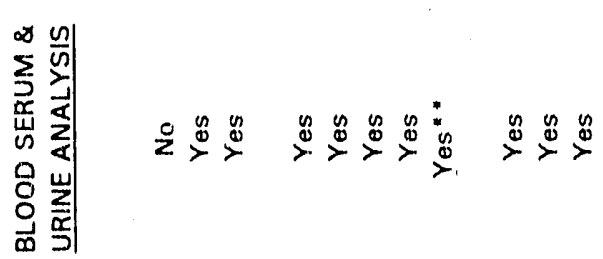
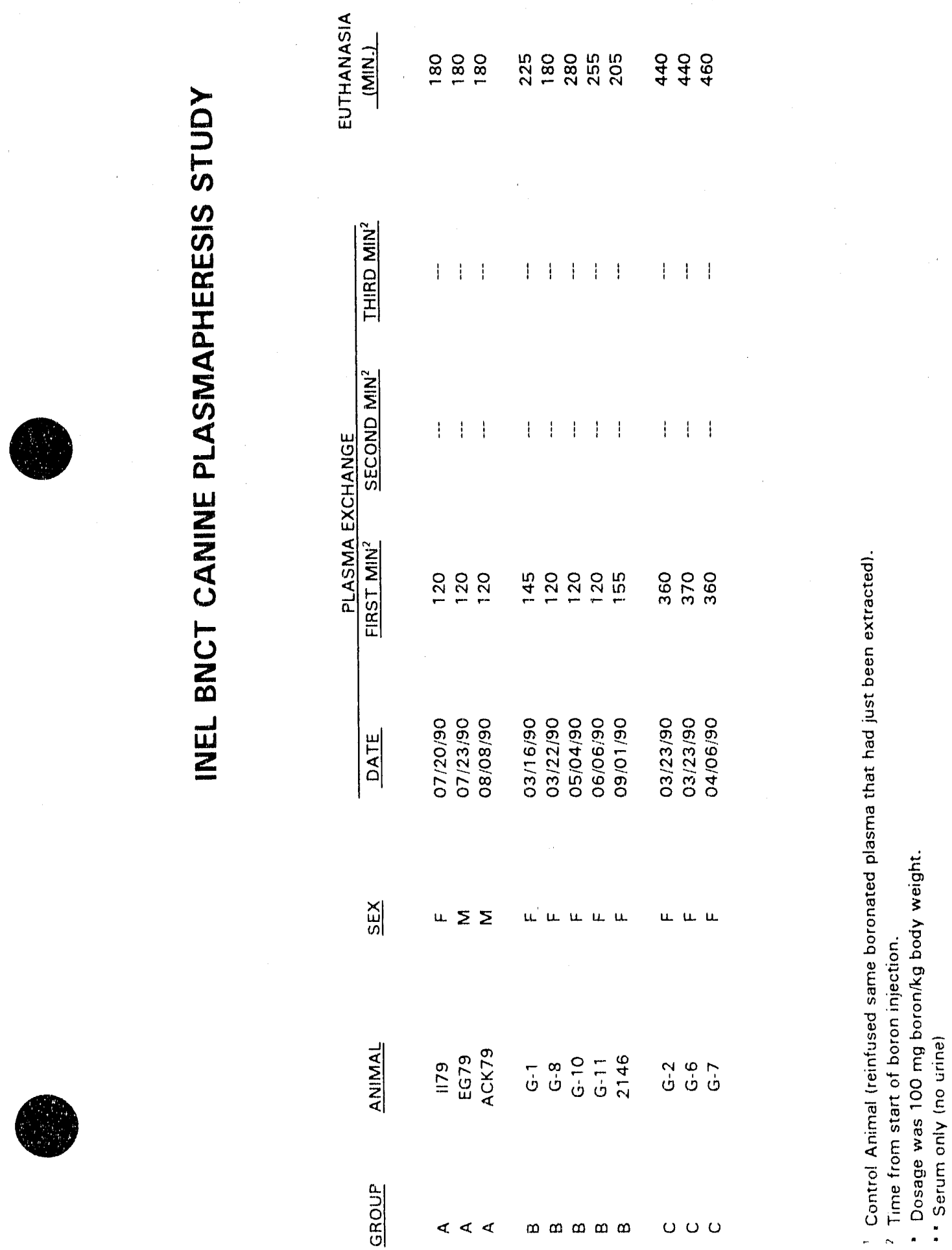


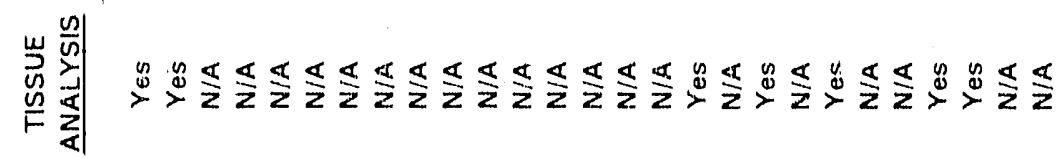

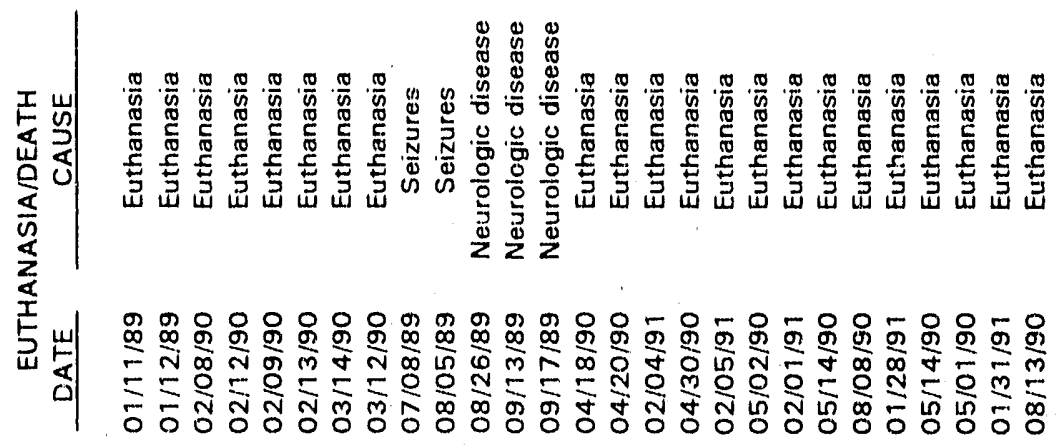

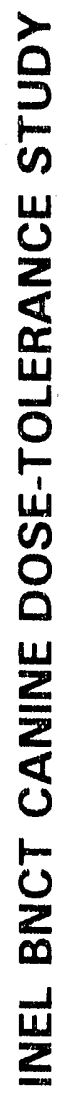

究

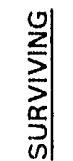

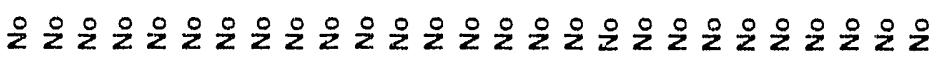

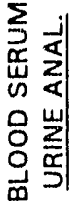

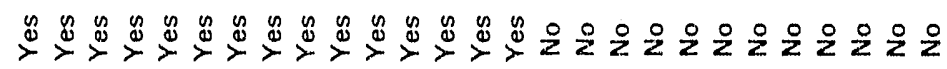

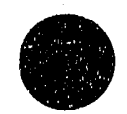

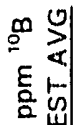

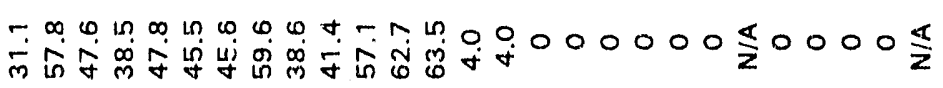

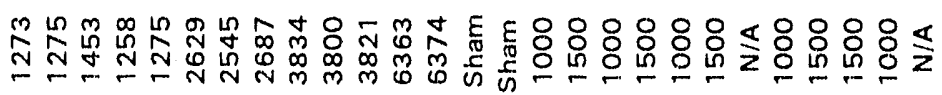

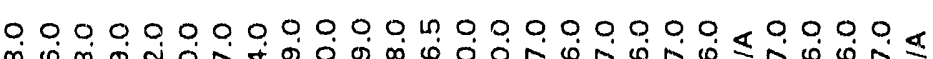

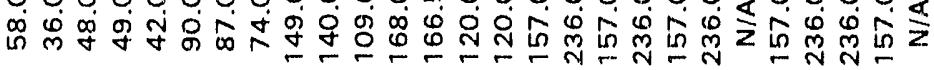

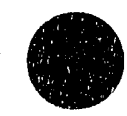

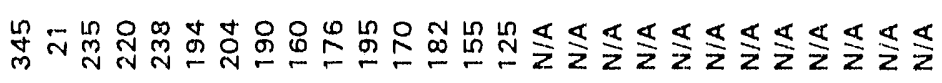

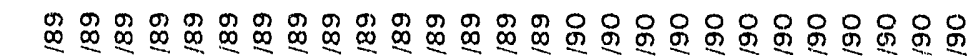

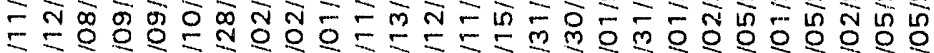

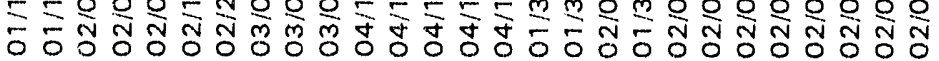

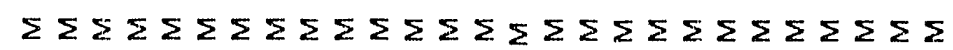

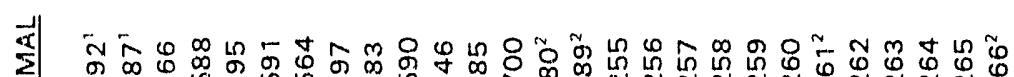

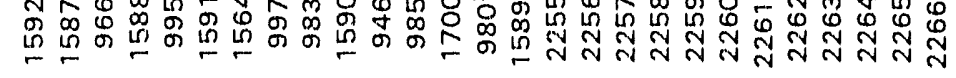



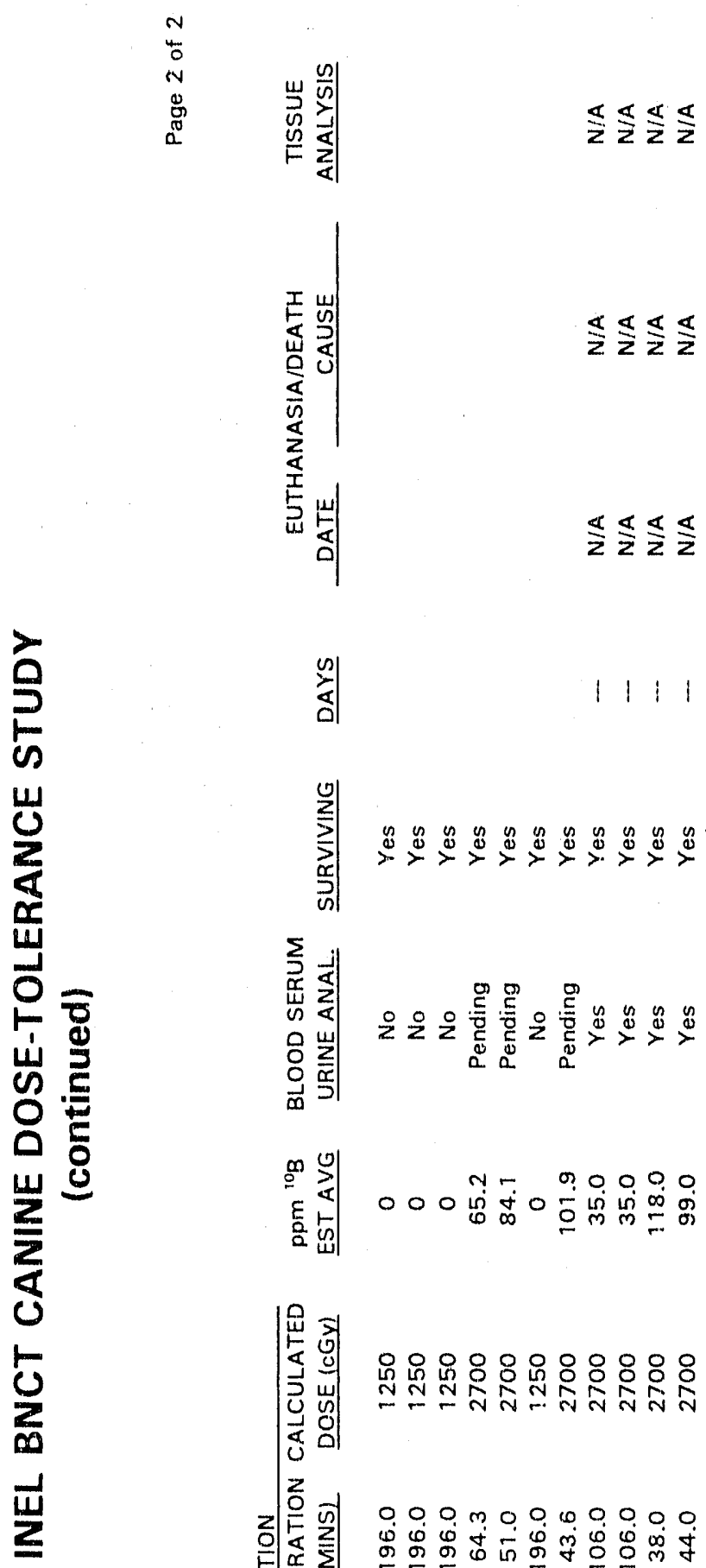

帘|

1111

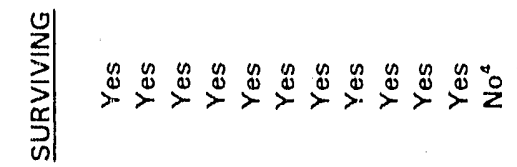

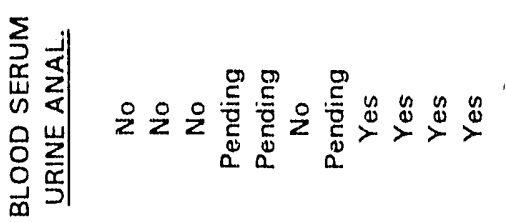

3

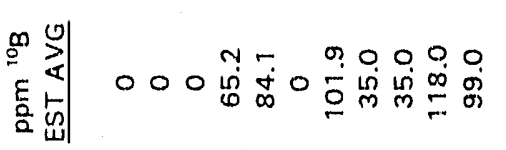

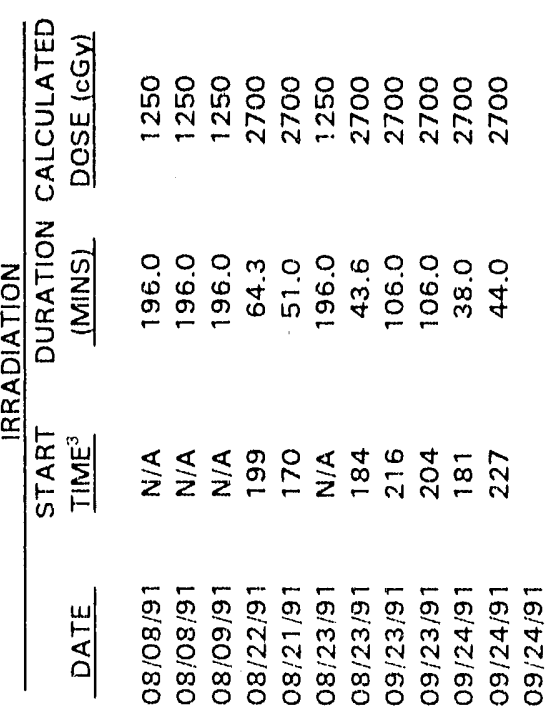

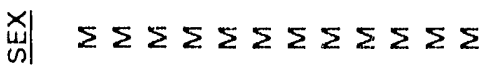

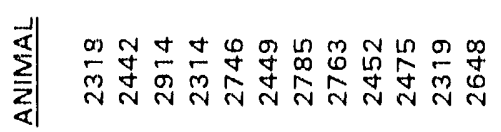

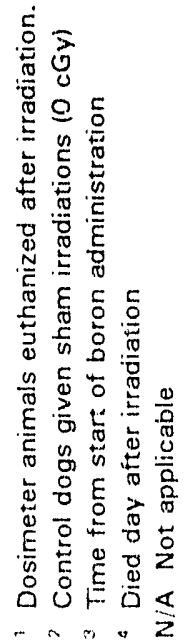




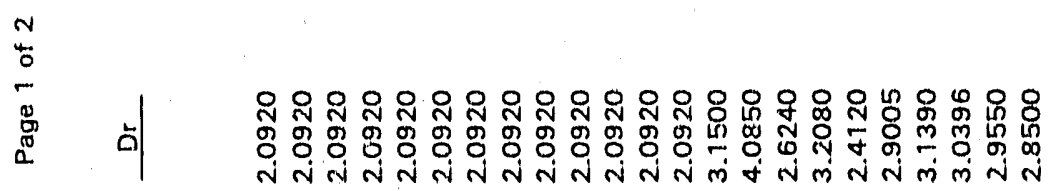

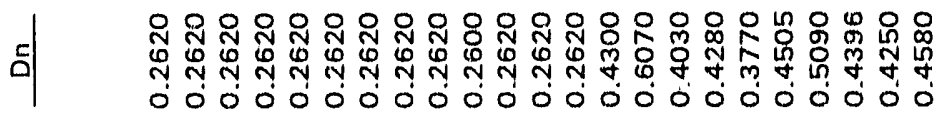

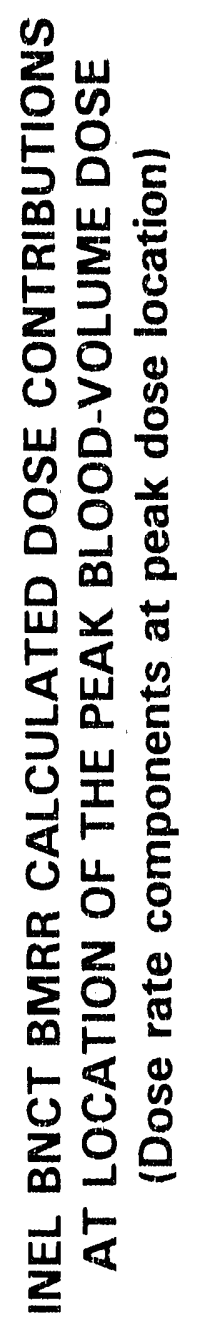

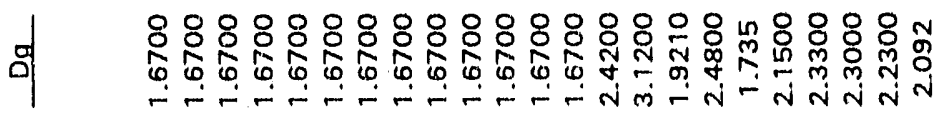

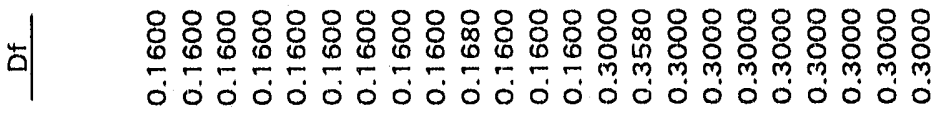

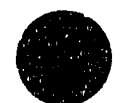

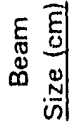

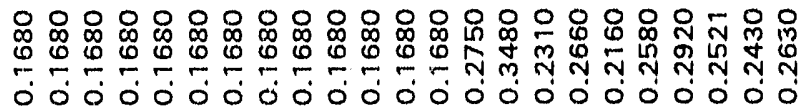

ㅇำ

으응으으응ㅇㅇㅇㅇㅇㅇㅇ으으으응ㅇㅇㅇㅇㅇㅇㅇㅇ으으으으으음 $\times \times \times \times \times \times \times \times \times \times \times \times \times \times \times \times \times \times \times \times \times \times \times$

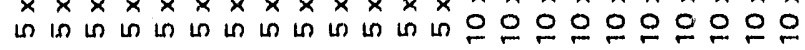

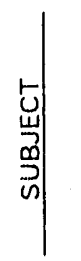

竞

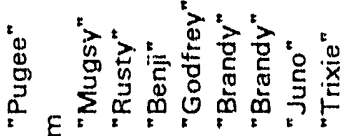

कृ

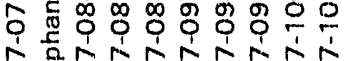

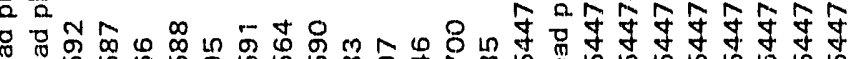

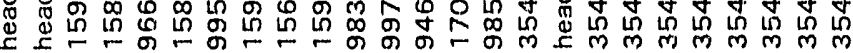

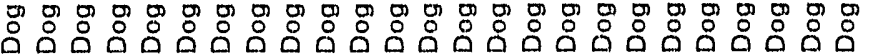

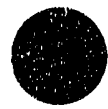

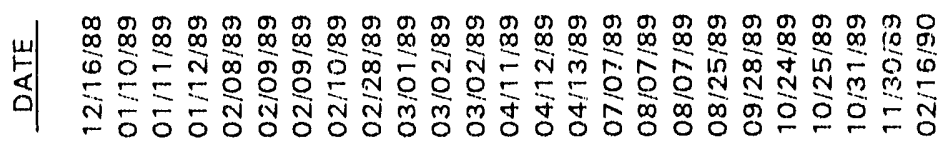

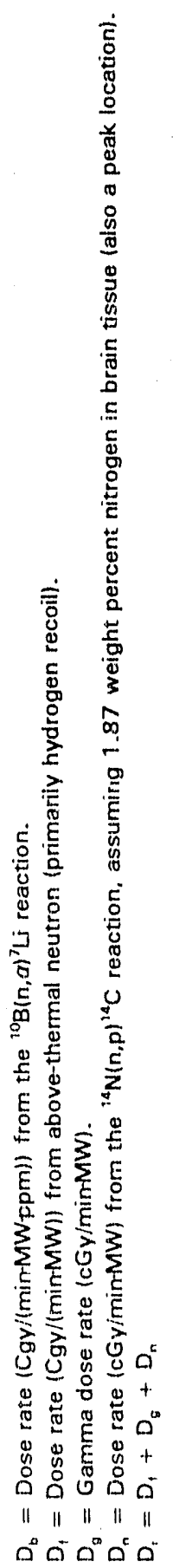




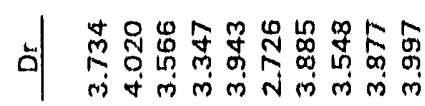
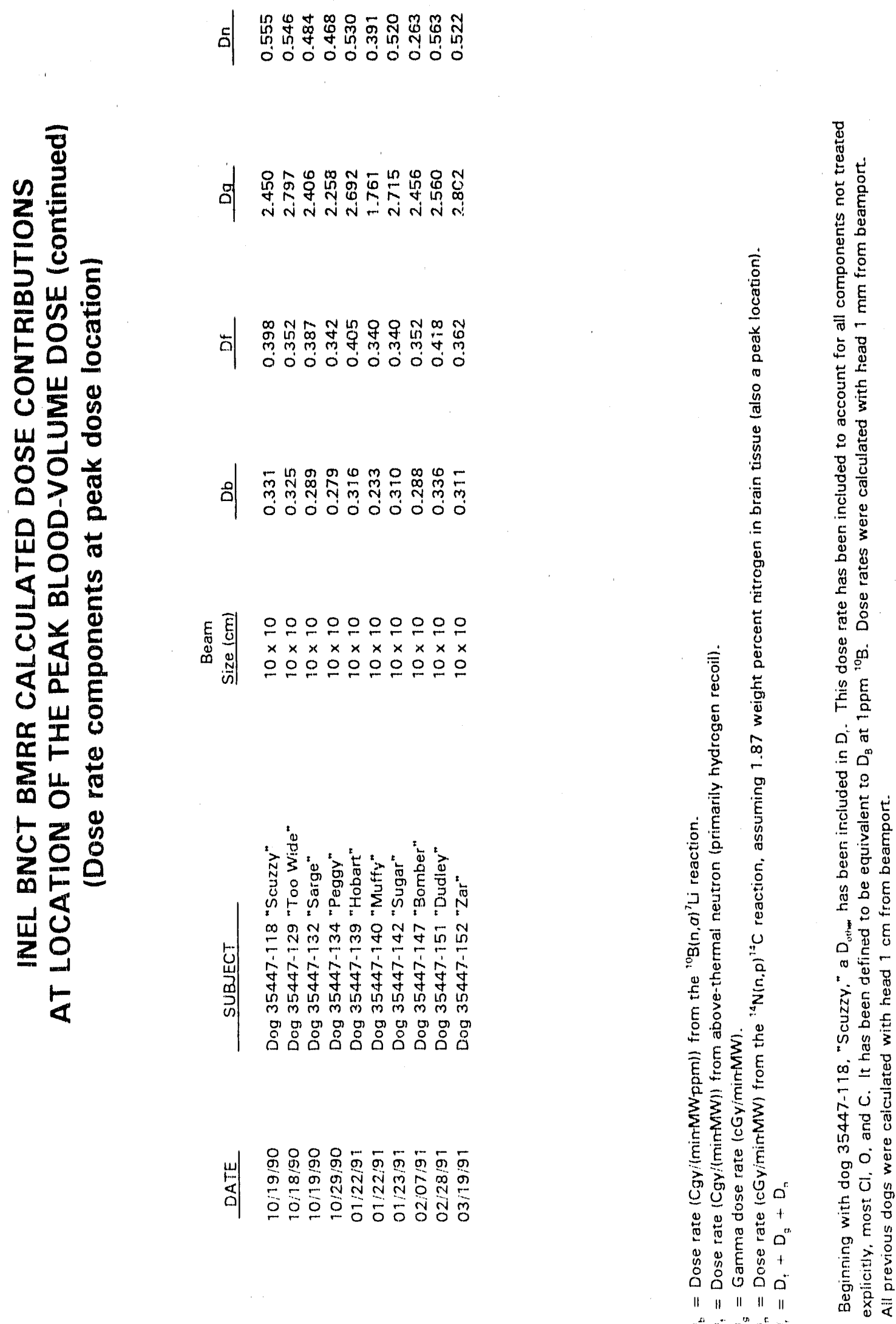

แ 웅용유

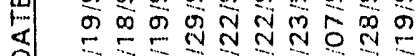

응응응ㅇํㅇํㅇ

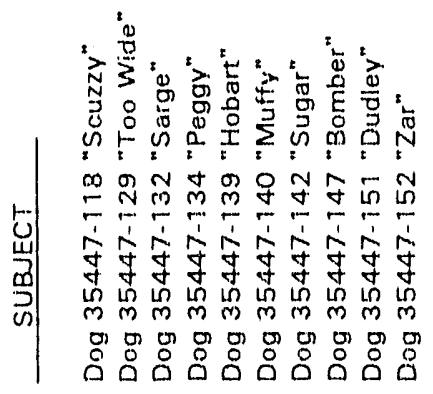




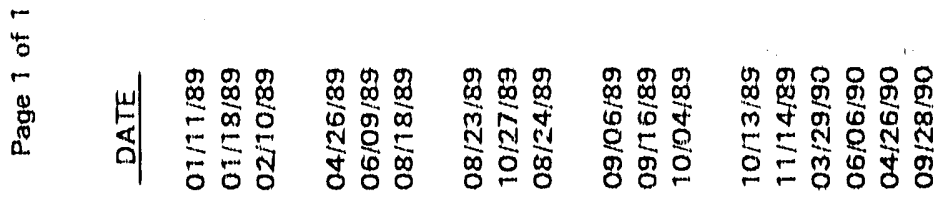

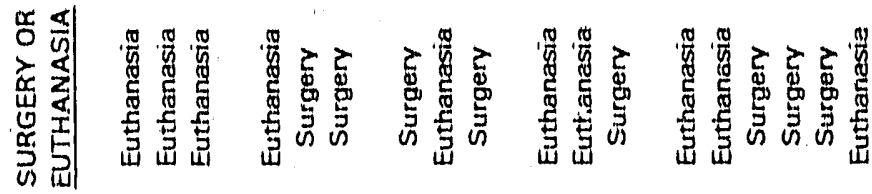

$\sum_{0}^{2}$

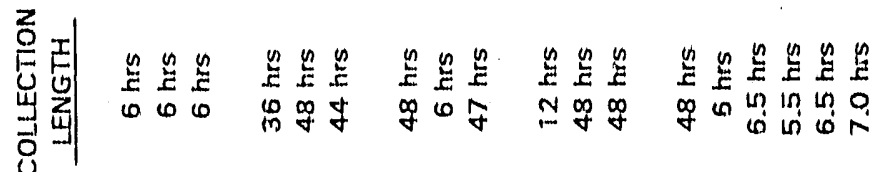

崖

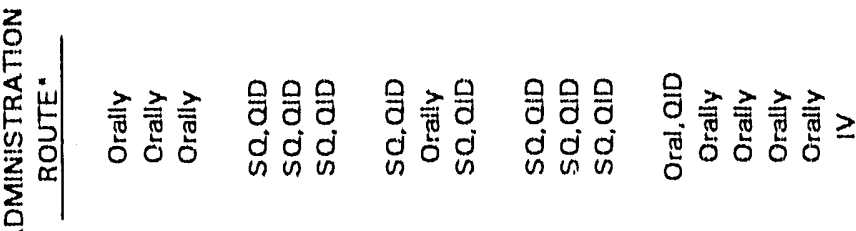

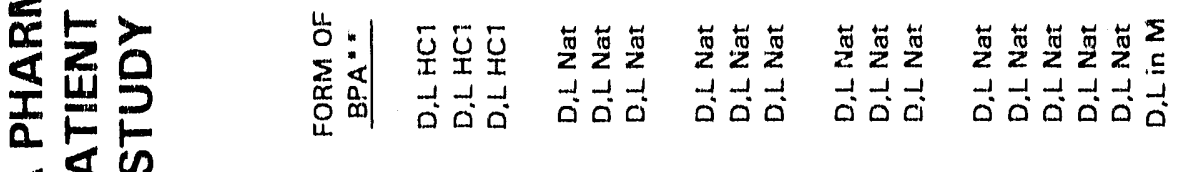

$B$

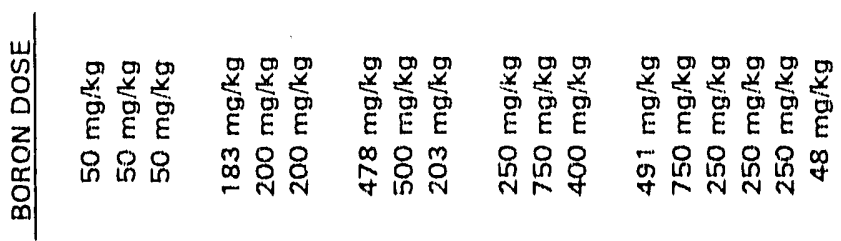

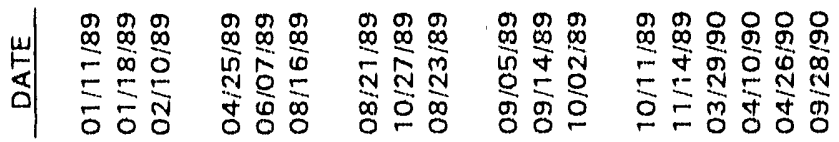

$\sum_{\substack{u \\ \frac{1}{2}}}^{\leftarrow}$

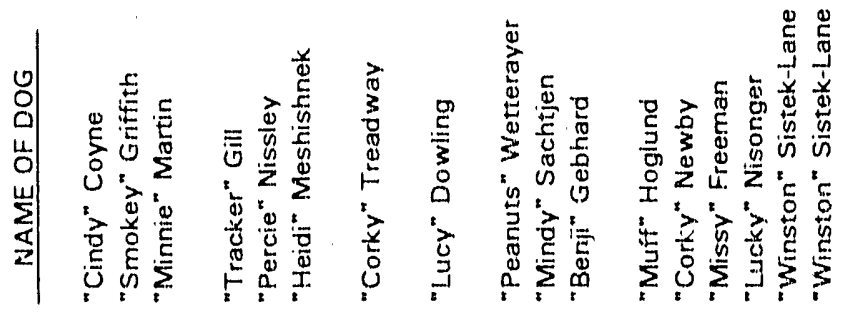

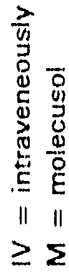

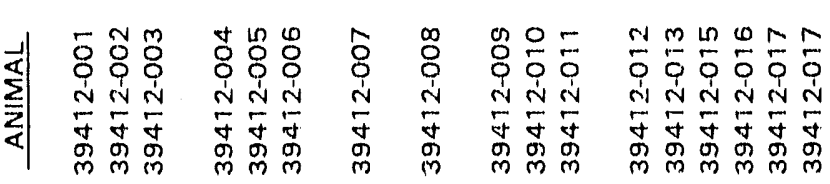

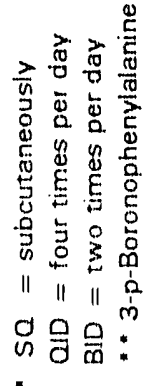




\title{
APPENDIX B
}

\author{
ACRONYMS
}




\section{Acronyms}

\begin{tabular}{|c|c|}
\hline AAPM & American Association of Physiclsts in Medicine \\
\hline ACS & American Chemical Society \\
\hline ADM & Action Description Mernorandum \\
\hline ANS & American Nuclear Society \\
\hline ASI & Atom Sclences, Inc. \\
\hline ASN & American Society of Neuroradiology \\
\hline ATCC & American Type Culture Collection \\
\hline ATR & Advanced Tost Reactor \\
\hline AWU & Assoclated Western Universities \\
\hline $\mathrm{B} / \mathrm{C}$ & Boron-to-carbon \\
\hline BME & Easal minimum Eagle \\
\hline BMRR & Brookhaven Medical Research Reactor \\
\hline BNL. & Brookhaven Natlonal Laboratory \\
\hline BNCT & Boron Neutron Capture Therapy \\
\hline BPA & Boronophenylalanine \\
\hline BSA & Bovine serum albumin \\
\hline BSH & Borocaptate Sodium $\left(\mathrm{Na}_{2} \mathrm{~B}_{12} \mathrm{H}_{11} \mathrm{SH}\right)$ \\
\hline$B S S(B)$ & $\mathrm{B}_{24} \mathrm{H}_{22} \mathrm{SS}^{4}$ \\
\hline $\mathrm{BSSO}(B)$ & $\mathrm{B}_{24} \mathrm{H}_{22} \mathrm{~S}_{2} \mathrm{O}^{4}$ \\
\hline CAT & Corrective Action Team \\
\hline CCF & Change control form \\
\hline$C D$ & Contrast diaphragm \\
\hline CHNS & Carbon-hydrogen-riltrogen-sulfur \\
\hline COCA & Consent Order Compliance Agency \\
\hline CR-39 & Allyl diglycol carbonate \\
\hline CRADA & Cooperative Research and Development Agreement \\
\hline CRF & Corticotropin releasing factor \\
\hline $\mathrm{CRH}$ & Corticotropin releasing hormone \\
\hline CSF & Cerebrospinal Fluld \\
\hline CSI & Chemical shift Imaging \\
\hline CT & Computed tomography \\
\hline$D \& D$ & Decontamination and decommissioning \\
\hline DEA & Diethanolamine \\
\hline DMAP & Diemethylarninopyridine \\
\hline DMEM & Dulbeccos minimum essential medium \\
\hline DMS & Data Management System \\
\hline DOE & Department of Energy \\
\hline DOE-ER & Department of Energy-Energy Research \\
\hline DOE-HERAC & Department of Energy-Health and Environmental Research Advisory Committee \\
\hline DOE-HO & Department of Energy-Headquarters \\
\hline$D O E-1 D$ & Department of Energy-Idaho Operations Office \\
\hline DOE-NE & Department of Energy-Nuclear Energy \\
\hline DOE-OHER & Department of Energy-Office of Health and Environmental Research \\
\hline DOP & Detalled operating procedure \\
\hline DORT & Two-dimensional $S_{n} \operatorname{computer} \operatorname{cod} \theta$ \\
\hline DSPC & Distearoyl phosphatadyl choline \\
\hline EA & Environmental Assessment \\
\hline ECBNCT & European Collaboration on Boron Neutron Capture Therapy \\
\hline ECC & Elaidyl carborane carboxylate \\
\hline EDF & Engirieering Design File \\
\hline
\end{tabular}


EE

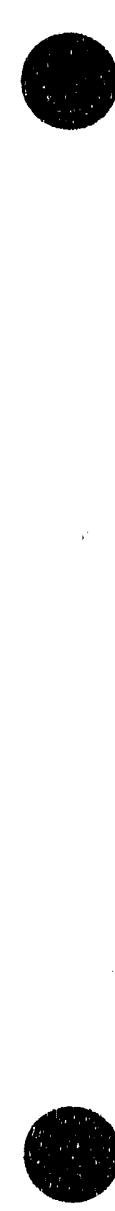

EGS

EGTA

EIRMC

EKG

EPA

EPRO

ERDP

ES\&H

ESMS

FCF

FDA

FIA

FMEA

$G A$

GE

GHRH

GIT-NRC

GTRR

HAT

HDW

HEPA

HERAC

HFR

HMPAO

HP

HPLC

HPLC.UV

IACUC

ICP-AES

ICP-MS

IM

IND

INEL

INPO

IP-RP-HPLC

ISU

IV

KURRI

LDL

LET

LOCA

LOFT/OECD

MCNP

MIT

MR

MRI

MRS

MSTI

MSU

NAS

NCAR

$\mathrm{NCl}$

NCS
Environmental Evaluation

Engineering Graphics Systems

othylene glycol-dls ( $\beta$-amlnoethyl ether) $M N, N, N^{\prime}, N^{\prime}-T e t r a a c e t i c$ acld

Eastern Idaho Reglonal Medical Center

Electrocardlogram

Environmental Protection Agency

Experimental Power Reactor Operator

Exploratory Research and Development Project

Environmental Safety and Health

Event Sequence and Monitoring System

Facillty Change Form

Food and Drug Administration

Flow Injection analysis

Failure Mode and Effects Analysis

General Atomics

General Electric

Growth hormone releasing hormone

Georgla Institute of Technology-Neeley Research Center

Georgla Tech Research Reactor

Hypoxanthane aminopterine thymidine

High pressure demineralized water

High-efficiency particulate air filter

Health Environmental Research Advisory Committee

High flux reactor

Hexamethyl-Propylene-Amineoxime

Hewlett-Packard

High Performance Liquid Chromatography

High Performance Liquid Chrornatography-UltraViolet

Institutional Animal Care and Use Committee

Inductively Coupled Plasma-Atomic Emission Spectroscopy

Inductively Coupled Plasma-Mass Spectrometry

Ion microscope

Investigational New Drug exemption from FDA

Idaho National Engineering Laboratory

Institute of Nuclear Plant Operations

Ion pair-reversed phase-high performance liquid chromatography

Idaho State University

Intravenous

Kyoto University Reactor Research Institute

Low density lipoprotein

Linear energy transfer

L.oss-of-coolant accident

Loss-of.Fluid Test/Organization of Economic Cooperation and Development

Three-dimensional Monte Carlo computer code

Massachusetts Institute of Technology

Magnetic resonance

Magnetic resonance imaging

Magnetic resonance spectroscopy

Mountain States Tumor Institute

Montana State University

National Academy of Sciences

National Center for Atmospheric Research

National Cancer Institute

Network computing system 
NIDE

NEPA

NESHAPS

NIM

NIST

NMR

NWI

OCT

OHSU

ORAU

ORNL

ORSU

OSF

OSHA

OSU

PBF

PDARS

PET

PMT

PNL

POM

PRP

PTC

OC/OA

RAP

RBE

RCRR

RESL

RF

RFP

RIS

RP.HPLC

RTT-MC

SAR

SDD

SIMS

SIRIS

TLD

TRA

TTAF

UC/Berkeley

UC/Davis

UCLA

UCSF

UOR

UofR

UofU

USDA

WAS

WSU
New Device Exemption (FDA)

National Environmental Policy Act

National Emission Standards for Hazardous Air Pollutants

National Institute of Medicine

National Institute of Science and Technology

Nuclear magnetic resonance

Northwest Imaging

A low-temperature adhesive

Oregon Health Sciences University

Oak Ridge Associated Universities

Oak Ridge National Laboratory

Oregon State University

Open Software Foundation

Occupational Safety Health Administration

Ohio State University

Power Burst Facility

Patient Data Acquisition and Retrieval System

Position Emission Tornography

Photo multiplier tube

Pacific Northwest Laboratory

Plant operating manual

Power Reactor Programs

Permit to Construct

Quality control/quality assurance

Requirements Awareness Program

Relative Biological Effectiveness

Reed College Research Reactor

Radiological and Environmentai Sciences Laboratory

Radiofrequency

Request for Proposal

Resonance ionization spectroscopy

Reversed phase-high performance liquid chromatography

Monte Carlo Transport Module

Safety Analysis Report

System Design Description

Secondary Ion Mass Spectrometry

Sputter-Initiated Resonance Ionization Spectroscopy

Thermoluminescent dosimeter

Test Reactor Area

Test Train Assembly Area Facility

University of California Berkeley

University of California Davis

University of California Los Angeles

University of California San Francisco

Unusual occurrence report

University of Rochester

University of Utah

United States Department of Agriculture

Work Authorization Statement

Washington State University 

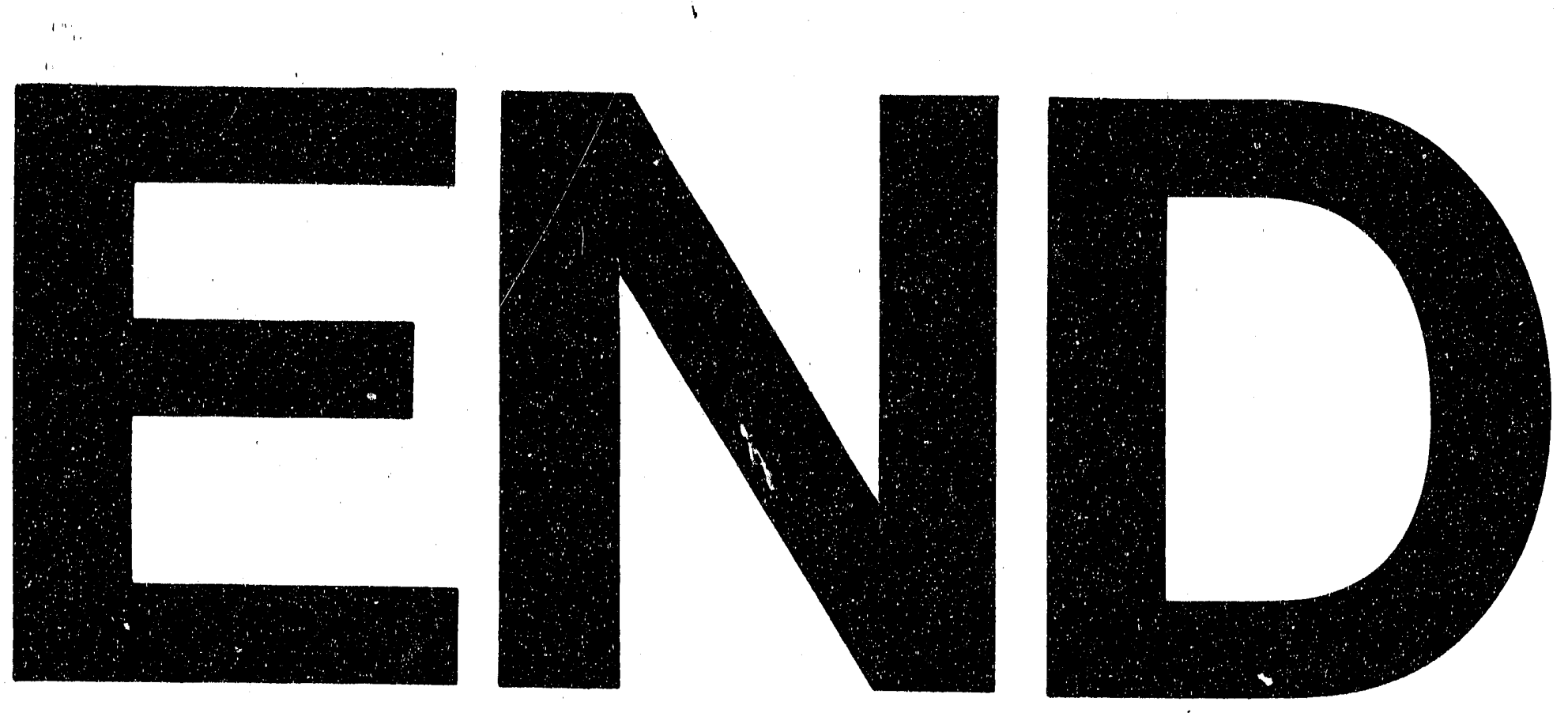

辯
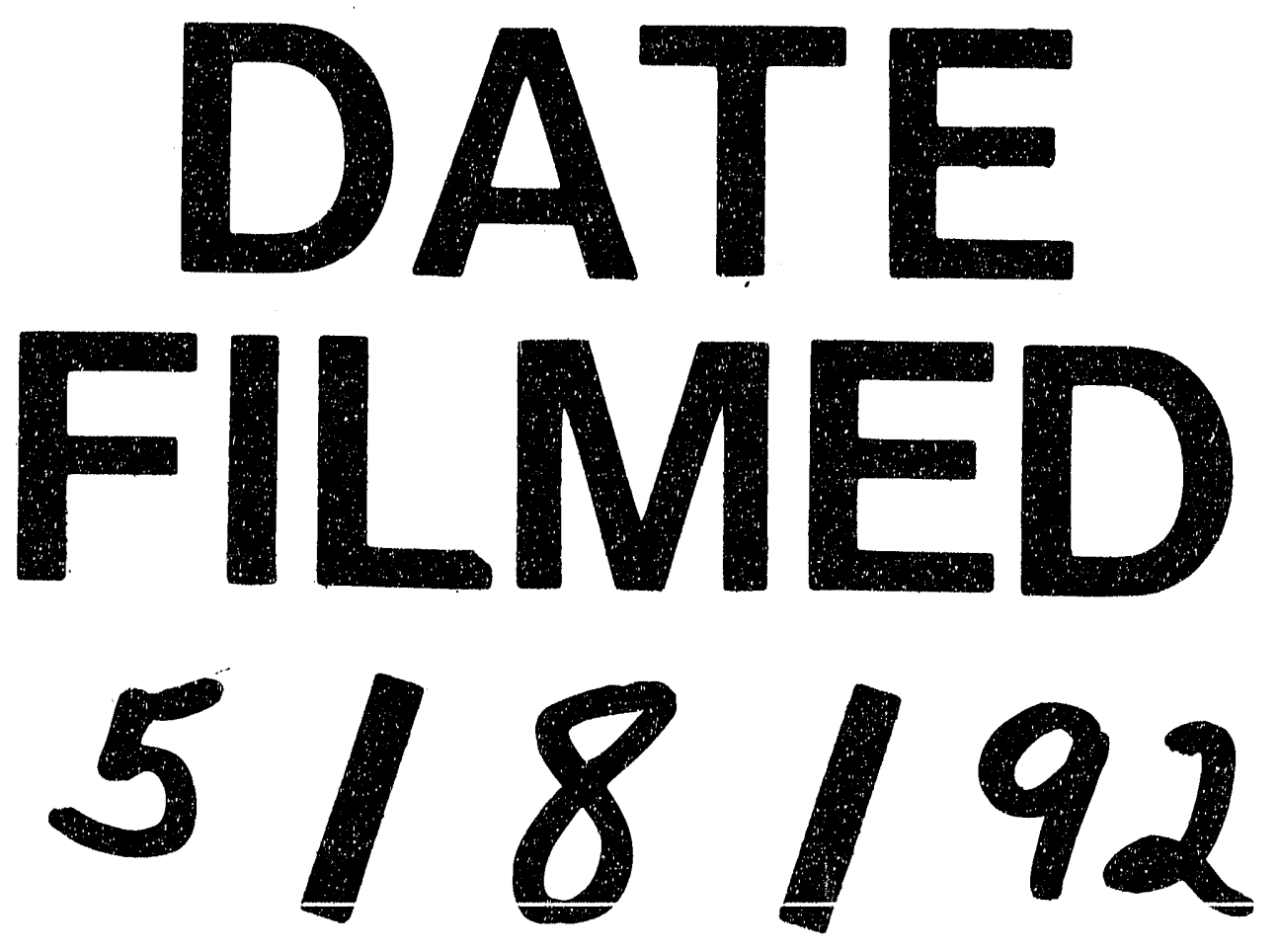
